\title{
Low-Dimensional Halide Perovskites and Their Advanced Optoelectronic Applications
}

\author{
Jian Zhang ${ }^{1} \cdot$ Xiaokun Yang ${ }^{1} \cdot$ Hui Deng ${ }^{1} \cdot$ Keke Qiao $^{1} \cdot$ Umar Farooq $^{1} \cdot$ Muhammad Ishaq $^{1} \cdot$ Fei $\mathbf{Y i}^{2} \cdot$ \\ Huan Liu ${ }^{2} \cdot$ Jiang Tang ${ }^{1} \cdot$ Haisheng Song ${ }^{1}$
}

Received: 13 December 2016/ Accepted: 16 January 2017/Published online: 13 March 2017

(C) The Author(s) 2017. This article is published with open access at Springerlink.com

\begin{abstract}
Metal halide perovskites are crystalline materials originally developed out of scientific curiosity. They have shown great potential as active materials in optoelectronic applications. In the last 6 years, their certified photovoltaic efficiencies have reached $22.1 \%$. Compared to bulk halide perovskites, low-dimensional ones exhibited novel physical properties. The photoluminescence quantum yields of perovskite quantum dots are close to $100 \%$. The external quantum efficiencies and current efficiencies of perovskite quantum dot light-emitting diodes have reached $8 \%$ and $43 \mathrm{~cd} \mathrm{~A}^{-1}$, respectively, and their nanowire lasers show ultralow-threshold room-temperature lasing with emission tunability and ease of synthesis. Perovskite nanowire photodetectors reached a responsivity of $10 \mathrm{~A} \mathrm{~W}^{-1}$ and a specific normalized detectivity of the order of $10^{12}$ Jones. Different from most reported reviews focusing on photovoltaic applications, we summarize the rapid progress in the study of low-dimensional perovskite materials, as well as their promising applications in optoelectronic devices. In particular, we review the wide tunability of fabrication methods and the state-of-the-art research outputs of low-dimensional perovskite optoelectronic devices. Finally, the anticipated challenges and potential for this exciting research are proposed.
\end{abstract}

Keywords Metal halide perovskites · Low-dimensional effect · Synthesis · Optoelectronic devices · Versatility

\section{Introduction}

Low-dimensional materials are nanocrystals with at least one dimension within the nanoscale range $(1-100 \mathrm{~nm})$. For the last few decades, they have been increasingly attracting interest as they exhibit unique properties. They are also

Haisheng Song

songhs-wnlo@mail.hust.edu.cn

1 Wuhan National Laboratory for Optoelectronics (WNLO), Huazhong University of Science and Technology (HUST), 1037 Luoyu Road, Wuhan 430074, Hubei, People's Republic of China

2 School of Optical and Electronic Information, Huazhong University of Science and Technology (HUST), 1037 Luoyu Road, Wuhan 430074, Hubei, People's Republic of China referred to as artificial atoms because the density of their electronic states can be widely and easily tuned by adjusting the crystal composition, size, shape, and so on. A typical example of the effect of size on crystal properties is quantum dots (QDs), whose three dimensions are all in the nanoscale range. The bandgaps could be easily tuned by adjusting the dot size [1]. A variety of optoelectronic applications have been explored for low-dimensional perovskites such as photovoltaics, light sensors, light-emitting diodes (LEDs), owing to the strong light-matter interaction [2]. Unlike traditional semiconductor nanomaterials, low-dimensional halide perovskites can be prepared at low cost and by solution-processable techniques. They have demonstrated superior optical, magnetic, dielectric, electrical, and optoelectronic properties [3-5] and have been becoming a hot research topic in new semiconductor materials and optoelectronic devices. 
The origin of "Perovskite" is calcium titanate $\left(\mathrm{CaTiO}_{3}\right)$, which was discovered by Russian mineralogist L.A. Perovski in 1839. After that, perovskite was defined as a class of compounds that have the same crystal structure as $\mathrm{CaTiO}_{3}$, known as the perovskite structure [7]. The general chemical formula for pure perovskite compounds is $\mathrm{ABX}_{3}$ (Fig. 1a) where "A" and "B" are two cations of dissimilar size, and $\mathrm{X}$ is an anion that binds to both. Chalcogenide perovskites $\left(\mathrm{AMO}_{3}\right)$ are formed from divalent $A^{\mathrm{II}}$ $\left(\mathrm{Mg}^{2+}, \mathrm{Ca}^{2+}, \mathrm{Sr}^{2+}, \mathrm{Ba}^{2+}, \mathrm{Pb}^{2+}\right)$ and tetravalent $\mathrm{M}^{\mathrm{IV}}$ $\left(\mathrm{Ti}^{4+}, \mathrm{Si}^{4+}, \mathrm{Fe}^{4+}\right)$ elements with $\mathrm{O}^{2-}$ as the chalcogenide anion. Halide perovskite $\left(\mathrm{AMX}_{3}\right)$ represents a large collateral series of the perovskite family, and it is reasonable to divide them roughly into alkali-halide perovskite and organometal halide perovskite. The first category is mainly formed from the monovalent cations $\left(\mathrm{Li}^{+}, \mathrm{Na}^{+}, \mathrm{K}^{+}, \mathrm{Rb}^{+}, \mathrm{Cs}^{+}\right.$; aliphatic or aromatic ammonium) and the divalent $\mathrm{M}^{\mathrm{II}}\left(\mathrm{Be}^{2+}, \mathrm{Mg}^{2+}, \mathrm{Ca}^{2+}\right.$, $\left.\mathrm{Sr}^{2+}, \mathrm{Ba}^{2+}, \mathrm{Zn}^{2+}, \mathrm{Ge}^{2+}, \mathrm{Sn}^{2+}, \mathrm{Pb}^{2+}, \mathrm{Fe}^{2+}, \mathrm{Co}^{2+}, \mathrm{Ni}^{2+}\right)$ with $\mathrm{X}$ representing halogen anions $\left(\mathrm{F}^{-}, \mathrm{Cl}^{-}, \mathrm{Br}^{-}, \mathrm{I}^{-}\right)$. Oxide-based perovskites have been extensively studied, owing to their superior ferroelectric, magnetic, and superconductive properties [8]. The first halide-based perovskite structure was observed in cesium lead halides $\left(\mathrm{CsPbX}_{3}\right)$ by Moller in 1958. Their photoconductive properties could be tuned through varying halide components to achieve different spectral responses. The first appearance of the organic cation, methylammonium (MA), in halide perovskites was studied by Weber and Naturforsch in 1978 [9, 10].

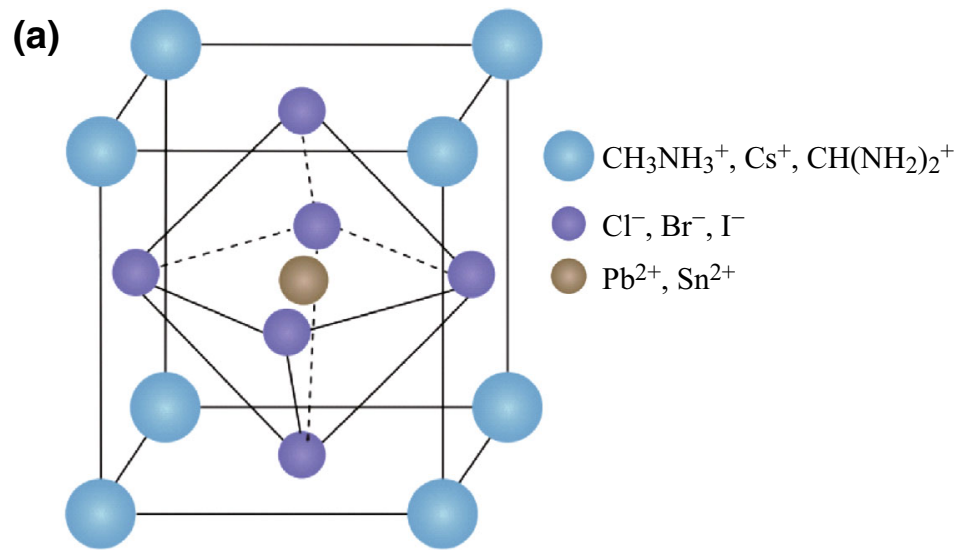

(b) Best Research-Cell Efficiencies

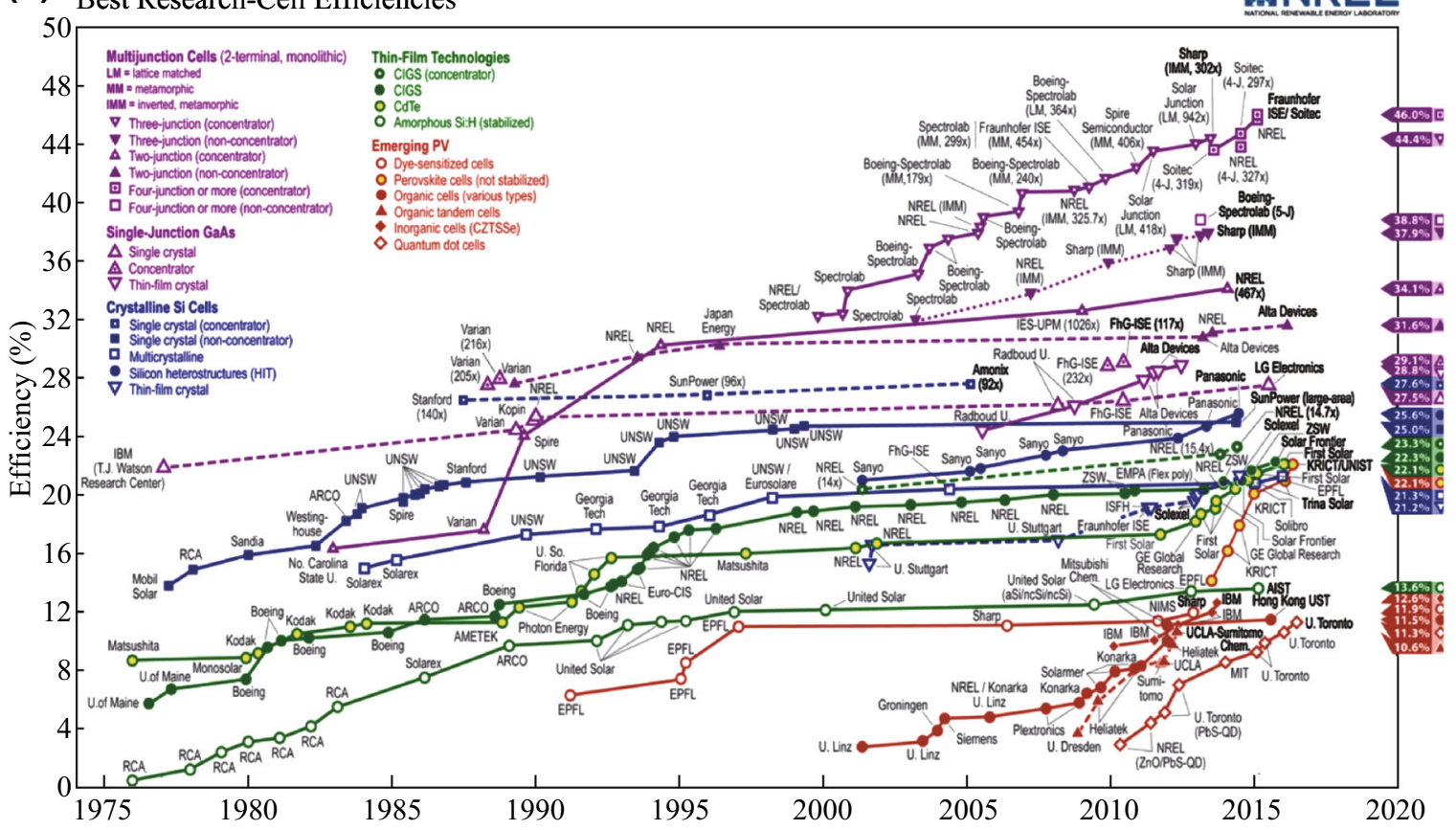

Fig. 1 Perovskite structure and solar cell efficiencies. a Perovskites possess the general crystal structure $\mathrm{ABX}_{3}$. The most prevalent perovskite in optoelectronic devices is MA lead trihalide, for which $A=\mathrm{CH}_{3} \mathrm{NH}_{3}, B=\mathrm{Pb}$, and $X=\mathrm{Cl}, \mathrm{Br}$ or I. b Best research cell efficiencies. Adapted image reproduced from NREL [6] 
In the 1990s, Mitzi [11] focused on layered organicinorganic halide perovskites that featured strong excitonic characteristics and demonstrated applications in thin-film transistors and LEDs. After Miyasaka et al.'s pioneered work in sensitized solar cells, the hybrid perovskite began its debut in photovoltaics in 2006 [12]. In 2009, a power conversion efficiency (PCE) of $3.8 \%$ was achieved by replacing $\mathrm{Br}$ with I [13]. In 2011, Park and coworkers achieved an efficiency of $6.5 \%$ by employing perovskite QDs as the sensitizers [14]. Later, Snaith et al. reported an efficiency of $10.9 \%$ utilizing solid electrolyte as a hole transport layer (HTL) [15]. As the study progressed, the superior properties of perovskites unfolded. Ambipolar carrier transport enlightened and promised the intensive employment of planar heterojunction devices [16-18]. This sparked an enormous development in the hybrid lead perovskite solar cells, which obtained a record PCE up to $22.1 \%$ in just 6 years using a low-cost solution method (Fig. 1b). In addition to PV applications, low-dimensional perovskite crystals with specific morphologies and ultrasmall size evoked new research interest in optoelectronic applications.

Compared with the hot research into halide perovskite thin-film solar cells, the low-dimensional perovskites hold great potential and just open a small angle. Thus, the present review mainly focuses on low-dimensional halide perovskite to summarize their synthesis methods, optoelectronic applications, and development outlook. By analogy to the human lifetime, the present stage of research into low-dimensional halide perovskites is just in its infancy. The high quantum yield, narrow full-width-at-half-maximum (FWHM), and tunable emission color of low-dimensional perovskite materials make them bright prospects for novel optoelectronic devices. A variety of monochromatic LEDs have been fabricated at room temperature utilizing inorganic cesium lead halide perovskite QDs as the color conversion layer, which have exhibited the best perovskite LED performance so far. Simultaneously, a hybrid perovskite nanowire photodetector (PD) with a photoconductive gain approaching $10^{14}$ electrons per photon and a responsivity approaching $6.0 \times 10^{5} \mathrm{~A} \mathrm{~W}^{-1}$ has been developed. Singlecrystal lead halide perovskite nanowire lasers exhibited ultralow lasing thresholds $\left(220 \mathrm{~nJ} \mathrm{~cm}^{-2}\right)$ and high quality factors $(\mathrm{Q} \sim 3600)$ at a charge carrier density of $\sim 1.5 \times 10^{16} \mathrm{~cm}^{-3}$. As hybrid perovskite researchers investigate more deeply, many amazing properties are expected to be uncovered beyond photovoltaics.

In this review, we present a thorough treatment of the recent developments in the fundamental material properties of low-dimensional perovskites (QDs, nanowires, and nanosheets). We mainly focus on the synthesis, unique properties, and notable breakthroughs of perovskites, with optoelectronic applications in photovoltaics, LEDs, PDs, and lasers. Finally, the near-future challenges and the potential directions of this exciting research area are forecasted.

\section{Crystal Structure and Tunability of Halide Perovskite}

Perovskites, with general formula $\mathrm{AMX}_{3}$, are a well-known class of inorganic materials with widespread deployment in ferro- and piezoelectric, magnetoresistive, semiconducting, and catalysis applications. The rich diversity is attainable owing to the multitude of large bivalent cations occupying the A-site (e.g., $\mathrm{Ca}^{2+}, \mathrm{Sr}^{2+}, \mathrm{Ba}^{2+}$ ), the smaller tetravalent cations (e.g., $\mathrm{Ti}^{4+}, \mathrm{Zr}^{4+}$ ) at the $\mathrm{M}$ site, and oxygen anions located at the $\mathrm{X}$-site. Halide perovskites are different from their classical chalcogenide counterparts with monovalent moieties introduced at the A-site, divalent metal cations at the $\mathrm{M}$ site, and typically halides at the $\mathrm{X}$-site. The $\mathrm{AMX}_{3}$ hybrid perovskite structure is formed by a three-dimensional (3D) network, with A-site cations occupying the cavity between four adjacent corner-sharing $\mathrm{MX}_{6}$ metal halide octahedra (e.g., $M=\mathrm{Pb}^{2+}, \mathrm{Sn}^{2+}, \mathrm{Ge}^{2+}, \mathrm{Cu}^{2+}, \mathrm{Eu}^{2+}, \mathrm{Co}^{2+}$ and $\left.X=\mathrm{Cl}^{-}, \mathrm{Br}^{-}, \mathrm{I}^{-}\right)$. The probability of forming the perovskite structure can be estimated using the Goldschmidt tolerance factor $(t)$ and the octahedral factor $(\mu)[12,19,20]$. Here, $t$ is based on the ionic radii $(r)$ of the $\mathrm{A}, \mathrm{M}$, and $\mathrm{X}$, constituenting in $t=\left(r_{A}+r_{X}\right) / \sqrt{2} \cdot\left(r_{M}+r_{X}\right)$, and $\mu$ is defined as $r_{\mathrm{M}} / r_{X}$. According to the tolerance factor, only the incorporation of small cations results in perovskite formation $(t \sim 1)$ because it is empirically found that cubic perovskites can form from $0.80<t<0.90$ and $0.40<\mu<0.90$ $[12,20-22]$. This implies that the large ionic radii of $\mathrm{Pb}$ $(1.19 \AA$ ) and the halides (e.g., iodide $2.20 \AA$ ) limit the ionic radius of the monovalent A cation to $2.9 \AA$. Therefore, only two or three $\mathrm{C}-\mathrm{C}$ or $\mathrm{C}-\mathrm{N}$ bonds or inorganic cations such as $\mathrm{Cs}^{+}(1.88 \AA)$ are expected to fit in the 3D hybrid perovskite structure [22].

One of the major advantages over traditional inorganic oxide is the low energy barrier to halide perovskite formation. A crystalline phase can be readily obtained by merely mixing and grinding the precursor salts at room temperature. Although this method suffers from a lack of precise experimental control, it exemplifies the ease with which the cations can diffuse into the inorganic framework. Typically, halide perovskites are synthesized via wetchemistry routes, allowing mixing at a molecular level, and resulting in materials with a pure phase. By carefully controlling the reaction conditions (e.g., temperature, solvent, ligands), halide perovskites of various morphologies (0D to 3D) and sizes (ranging over six orders of magnitude) can be prepared. For example, $\mathrm{CH}_{3} \mathrm{NH}_{3} \mathrm{PbBr}_{3}$ single crystals with a size of $5 \times 5 \times 2 \mathrm{~mm}^{3}$ are obtained within a growth period of several hours by exploiting its lower 
solubility in solvents at elevated temperatures [23]. $\mathrm{CH}_{3-}$ $\mathrm{NH}_{3} \mathrm{PbBr}_{3}$ nanoparticles (NPs) [24-27], layered sheets $[28,29]$, and nanowires (NWs) $[30,31]$ could be prepared via tuning the synthesis strategy.

These examples briefly demonstrated the robust synthesis processes with which a wide scale of nanostructured perovskites can be synthesized. In recent years, nanomaterials have become more and more interesting, as the novel physical properties are only observed at the nanoscale range, in contrast to their larger-scale counterparts. Fine control over synthesis conditions (precursor concentration, reaction temperature, choice of ligands, etc.) could introduce new physical properties, such as quantum size effects [32] or anisotropic growth [33], to fulfill future application requirements.

\section{Synthesis and Fundamental Properties of Low- Dimensional Halide Perovskites}

\subsection{Quantum Dots}

QDs, combining unique optical and electrical properties and solution-processed advantages, have been studied intensively for decades. Here, we will cover the evolution of halide perovskite QDs and devices for light-emission applications. We will disclose the physical and chemical characteristics and analyze the rich diversity in composition and structure.

To date, most reports of hybrid perovskite NPs have utilized the distinct strategy of ligand-assisted reprecipitation (LARP) method. This method could fabricate highluminescence and color-tunable colloidal $\mathrm{CH}_{3} \mathrm{NH}_{3} \mathrm{PbI}_{3}$ QDs with an absolute quantum yield (QY) up to $70 \%$ (Fig. 2). Polar solvents, capable of dissolving the inorganic lead and ammonium halide salts, are injected into a nonpolar "poor" solvent in the presence of coordinating ligands to stabilize the newly formed particles. It is noted that these syntheses are conducted at low temperature $\left(<80{ }^{\circ} \mathrm{C}\right)[25-28,32,33,35,36]$. Alternatively, $\mathrm{CsPbX}_{3}$ NPs could also be prepared using a hot injection method at higher temperatures ranging $140-200{ }^{\circ} \mathrm{C}$ under $\mathrm{N}_{2}$ atmosphere [37-40]. Here, the presence of oleic acid (OA) and oleylamine (OAm) ligands helps to inhibit crystal growth, passivate surface defects, and contribute to colloidal stability. This method has been successfully employed in the fabrication of high-quality inorganic semiconductor NPs [41]. One of the remarkable features of the hybrid perovskites is that no additional surface passivation is necessary to achieve high photoluminescence quantum yields (PLQYs), in contrast to traditional semiconductor QDs passivation, as the dangling bonds play a negligible role in the photoluminescence (PL) emission [37, 39].
The PLQY of QDs was gradually optimized by reaction and ligand selection. Utilizing long-chain ammonium bromide ligands, colloidal $\mathrm{CH}_{3} \mathrm{NH}_{3} \mathrm{PbX}_{3}$ cubic NPs $(\sim 6 \mathrm{~nm})$ produced using the LARP method [28] exhibited brightgreen PL emission at $527 \mathrm{~nm}$, with a PLQY of approximately 20\%. The increased reaction temperatures $\left(\sim 120^{\circ} \mathrm{C}\right)$ yielding equal quantum efficiencies and PL emission wavelengths [42] showcased the rigidity and high reproducibility of the above method. The synthesis was further optimized by increasing the organic/inorganic precursor ratios. This could narrow the PL emission $(\mathrm{FWHM}=30 \mathrm{~nm}$ at $520 \mathrm{~nm})$ and significantly improve PLQY values to a new record of 83\% [25]. Quantization effects were observed for 1.8- to 3.6-nm-sized $\mathrm{CH}_{3} \mathrm{NH}_{3}$ $\mathrm{PbBr}_{3} \mathrm{NPs}[27,43]$. The highest PLQY $\sim 93 \%$ was recorded from the supernatant phase of centrifugation [25, 28].

Despite the high PLQY and colloidal stability of methylammonium halide NPs ( $>5$ months of storage in air under dark conditions [25]), a major shortcoming arises from its instability in polar solvents. To overcome this limit, Vybronyi et al. synthesized $\mathrm{CH}_{3} \mathrm{NH}_{3} \mathrm{PbX}_{3} \mathrm{NPs}$ without using polar solvents [44]. Although the precipitate displayed lower quantum efficiencies $(25-50 \%)$ than previously reported $\mathrm{CH}_{3} \mathrm{NH}_{3} \mathrm{PbBr}_{3} \mathrm{NPs}$, it demonstrates an alternative synthesis route without the use of polar solvents. Other approaches involved the formation of $\mathrm{PbS} /$ $\mathrm{CH}_{3} \mathrm{NH}_{3} \mathrm{PbX}_{3}$ core-shell NPs via ligand-exchange reactions $[45,46]$. Light emission associated with $\mathrm{PbS} / \mathrm{CdS}$ NPs and $\mathrm{PbS} / \mathrm{CH}_{3} \mathrm{NH}_{3} \mathrm{PbI}_{3-x} \mathrm{Cl}_{x}$ core-shell NPs has also been reported [47].

Beyond the methylammonium halide perovskite materials, color-tunable full-inorganic $\mathrm{CsPbX}_{3}$ perovskite NPs (4-25 $\mathrm{nm}$ in diameter) utilizing a hot injection method in a temperature range of $140-200{ }^{\circ} \mathrm{C}$ (Fig. 3) have been reported [37]. The resulting NPs exhibited high PLQY of $50-90 \%$ and narrow emission linewidths of $1242 \mathrm{~nm}$. Owing to the large Bohr radius calculated for $\mathrm{CsPbCl}_{3}$ $(5 \mathrm{~nm}), \mathrm{CsPbBr}_{3}(7 \mathrm{~nm})$, and $\mathrm{CsPbI}_{3}(12 \mathrm{~nm})$, quantum confinement effects could be conveniently observed [37]. From transient absorption spectroscopy analysis, it was determined that the high PLQY arose from negligible electron-hole trapping pathways [48] and an average PL lifetime of 1-29 ns [34, 40, 48].

\subsection{Nanowires}

The high absorption coefficient enables it as an amazing absorber, which was first applied in dye-sensitized solar cells (DSSCs) to replace organic dye by Kojima et al. [13], Horvath et al. [49]. The further investigation shows that they not only play the role of the light absorbers, but also can be viewed both as electron- and hole-transporting media, owing to their ambipolar charge transport character 


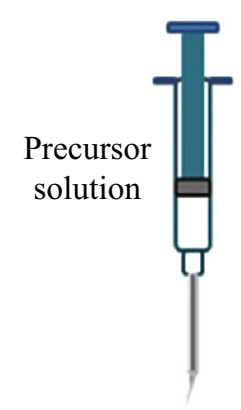

(a)

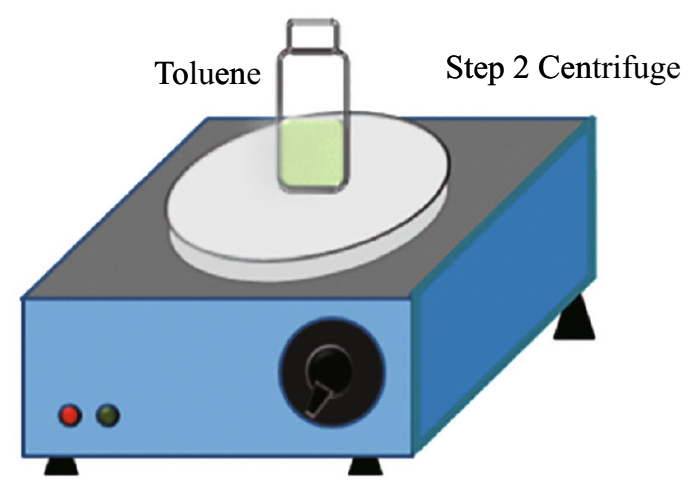

(c)

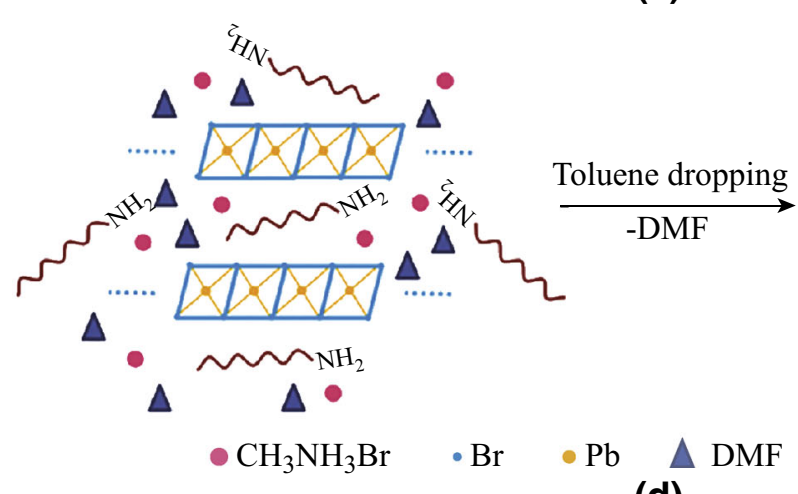

(d)

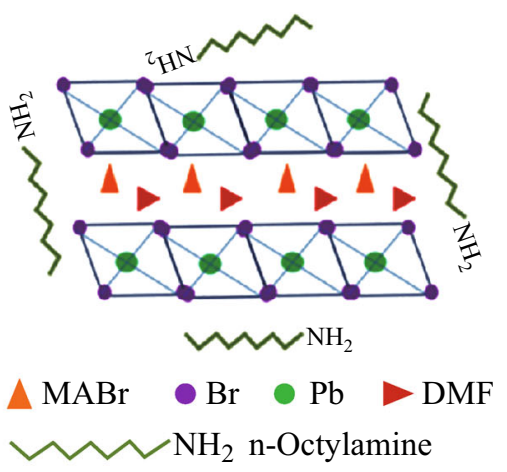

(b)
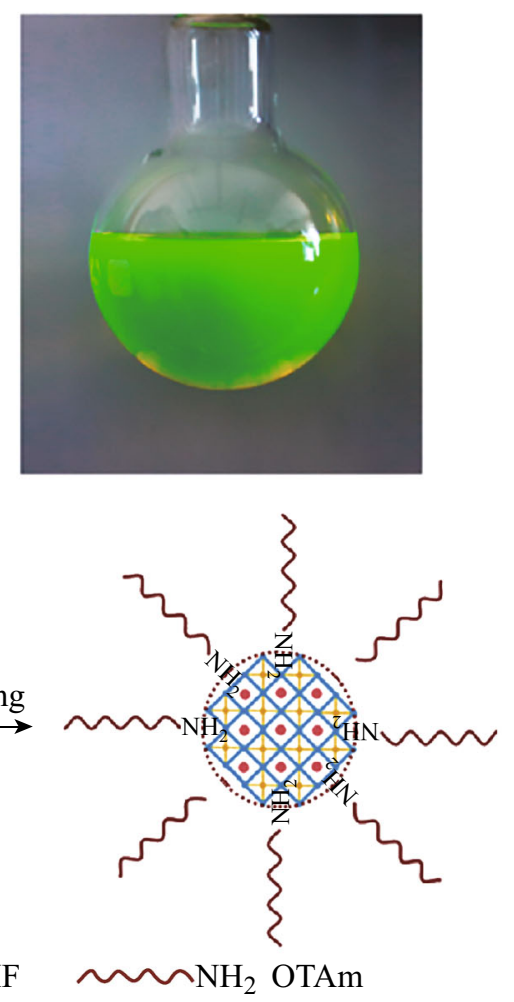

Fig. 2 Synthesis of $\mathrm{CH}_{3} \mathrm{NH}_{3} \mathrm{PbBr}_{3}$ QDs. Schematic illustration of the reaction system (a) and precursors (b). c Optical image of colloidal $\mathrm{CH}_{3} \mathrm{NH}_{3} \mathrm{PbBr}_{3}$ solution. d Schematic illustration for the formation of the $\mathrm{CH}_{3} \mathrm{NH}_{3} \mathrm{PbBr}_{3}$ QDs. Adapted image reproduced with permission of Ref. [27, 34]

[50]. In perovskite film synthesis, a nonporous homogenous perovskite film must be deposited in order to avoid shunting in planar devices. However, films produced by conventional spin coating methods were found to be comprised of large $\mathrm{CH}_{3} \mathrm{NH}_{3} \mathrm{PbI}_{3}$ microwhiskers and many uncovered void areas [51]. Dendrite crystal growth implies that organolead iodide perovskite (OIP) exhibits preferential growth. Inspired by that phenomenon, the synthesis of OIP nanowires (NWs) was investigated and implemented in our group [52]. In addition to our work, Swiss scientists Endre Horvá et al. pioneered the synthesis of OIP NWs by a simple slip coating method during a similar period [53].
The above two works opened the new research fields of halide perovskite NWs. The key synthesis methods and novel properties are summarized in chronological order.

\subsubsection{One-Step Evaporation-Induced Self-Assembly (EISA) Growth}

For the one-step method, the precursor solution (MAI and $\mathrm{PbI}_{2}$ in DMF) was cast on substrates, and then, the evaporation of the solvent resulted in supersaturated crystal growth with the $c$-axis parallel to the surface at room temperature [54]. The low symmetry (tetragonal $\mathrm{I} 4 / \mathrm{mcm}$ ) 

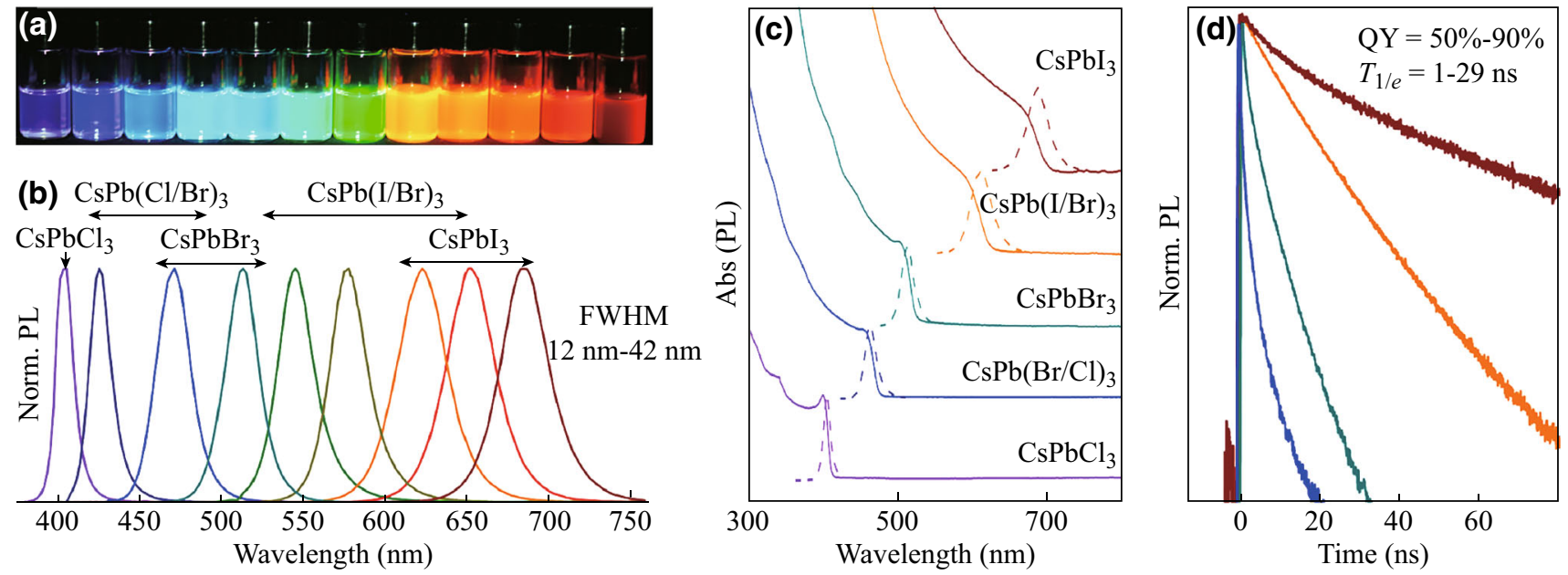

Fig. 3 Colloidal $\mathrm{CsPbX}_{3}$ perovskite $\mathrm{NCs}(X=\mathrm{Cl}, \mathrm{Br}, \mathrm{I})$ exhibit size- and composition-tunable bandgaps covering the entire visible spectral region with narrow and bright emission: a Colloidal solutions in toluene under UV lamp $(\lambda=365 \mathrm{~nm})$ excitation. b Representative PL spectra. c Typical optical absorption and PL spectra. d Time-resolved PL decays for all samples shown in $\mathbf{c}$ except $\mathrm{CsPbCl}_{3}$. Adapted image reproduced with permission of Ref. [37]

of OIP and strong intermolecular interactions may allow a preferred growth into NW morphology [55, 56]. For a high substrate temperature $\left(>120^{\circ} \mathrm{C}\right)$, it tended to grow homogeneously into NPs and suppress the preferential growth. Subsequent thermal annealing $\left(\sim 80^{\circ} \mathrm{C}\right)$ can help to convert the NWs precursor into perovskite NWs.

In most cases, self-assembled NWs by solution methods tend to distribute in a macroscopically random manner on substrates. The uniform distribution rather than NW bundles was implemented by UV-ozone treatment, owing to the improvement in surface DMF infiltration (Fig. 4d). The selective area growth and patterning of perovskite NWs were also implemented by UV-ozone treatment assisted by a shadow mask in our first $\mathrm{CH}_{3} \mathrm{NH}_{3} \mathrm{PbI}_{3} \mathrm{NW}$ work [58] (Fig. 4e). In addition, Endre Horvá et al. utilized two glass microscope slides sandwiching saturated $\mathrm{MAPbI}_{3} \mathrm{DMF}$ solution to shape an ultrathin $\mathrm{MAPbI}_{3}$ precursor solution in order to control the NW distribution. Combined variations of solvent concentration, temperature, fluidphilicity/phobicity, and sliding speed were utilized to control the crystallization kinetics, yielding tunable NW width, height, and length (Fig. 4a, b).

Our further work created a network-like NW web, which could satisfy the cross-linking and uniform NW distribution requirements to overcome the obstacles to NW applications [52]. In contrast to our previous drop-casting style, we adopt a spin coating method with suitable rotary speed and an annealing technique to obtain perovskite NW webs (Fig. 4g). All the NWs welded to each other without opening the end. The transparency of NWs webs could be facilely tuned by the precursor concentrations (Fig. 4h). The low-temperature fabrication process and web geometry promise high application potential in transparent and flexible optoelectronics. The usual one-step growth methods often achieve large diameter NWs over $200 \mathrm{~nm}$. Yang and coworkers added a surfactant solvent into the precursor to tune the NW crystallization kinetics [59] (Fig. 4i).

The application of low-dimensional NWs needs largescale growth to meet the wide application fields. The blade coating method enables the synthesis of aligned singlecrystalline OIP microwire (MW) arrays in terms of high yield and wafer size capability. Thus, Jie et al. first applied the doctor blade coating technique for large-scale and aligned NW growth [60]. It is well known that the highest efficiency deposition technique is printing. The low deposition temperature and one-step solution method promise potential applicability by printing methods. Recently, Yang et al. developed a large-scale roll-to-roll microgravure printing technique for perovskite NWs synthesis [61] (Fig. 4f). By systematic deposition recipe optimization, perovskite NW thin film was deposited on PET substrates (Fig. 4c).

\subsubsection{Two-Step Method Growth}

Similar to perovskite thin-film fabrication, researchers developed a two-step method in order to face the specific requirements. Without using a novel technique such as electrospinning, $\mathrm{MAPbI}_{3} \mathrm{NW}$ film was conveniently formed by two-step spin coating technology. They simply coated the $\mathrm{PbI}_{2}$ layer with an isopropanol solution of MAI in the presence of a small amount of polar aprotic solvent [30]. The NW diameters ranged from 30 to $200 \mathrm{~nm}$, much smaller than those obtained from a one-step solution method. The locally dissolved $\mathrm{PbI}_{2}$ may serve as a preferential site for reacting with MAI to grow a 1D structure, 

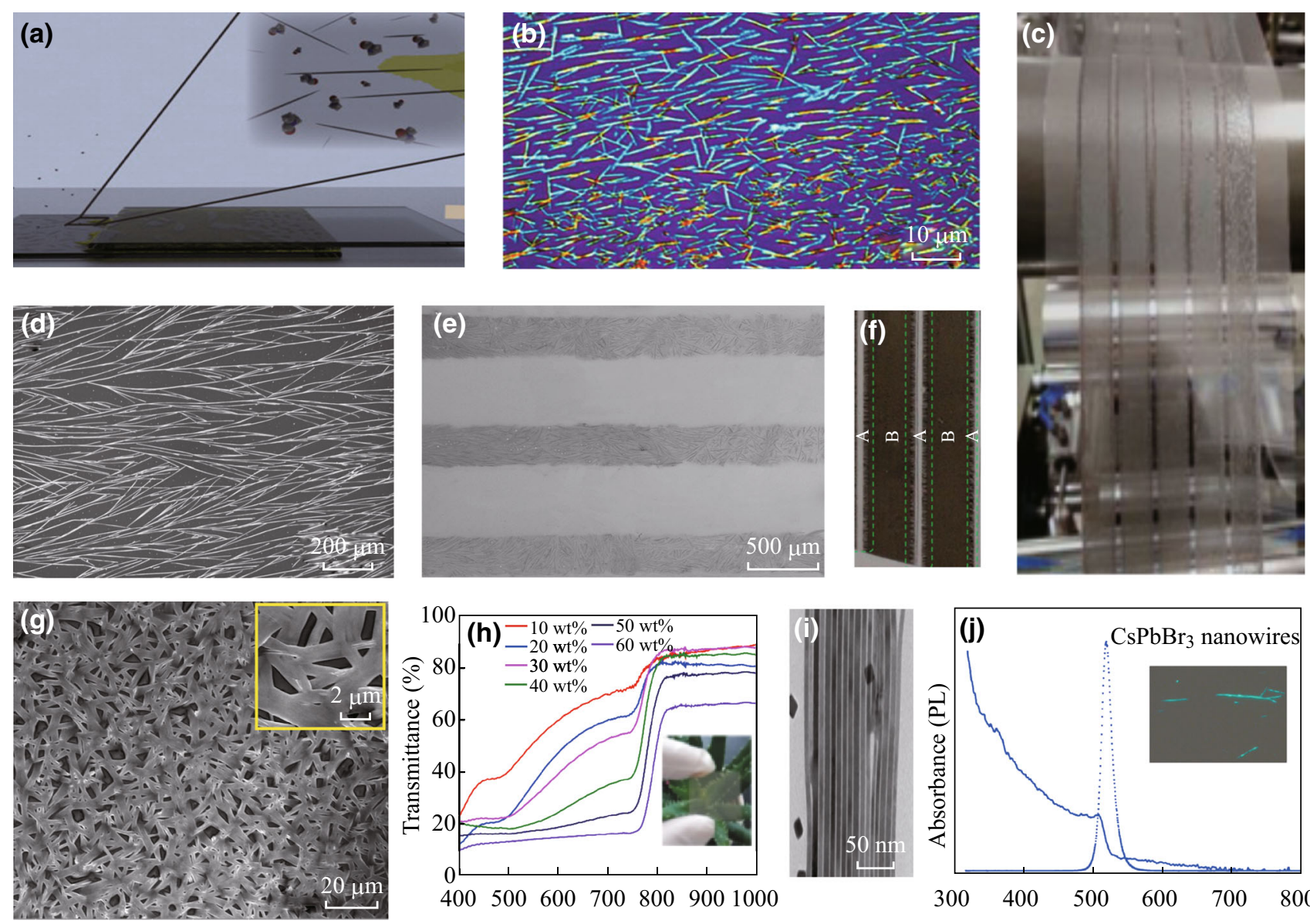

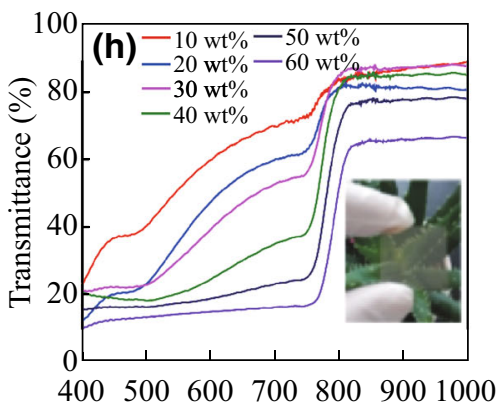

Wavelength (nm)
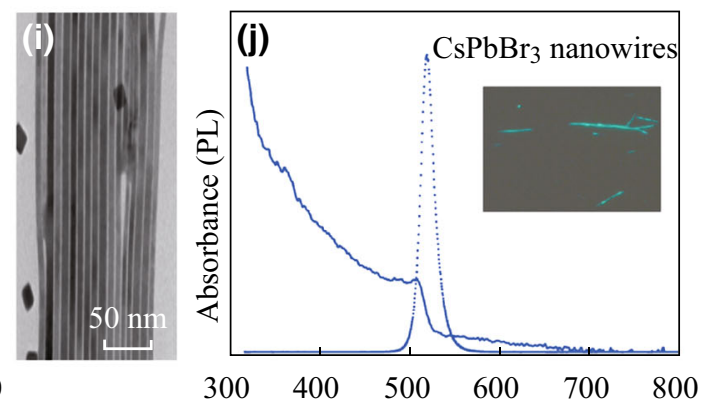

Wavelength (nm)

Fig. 4 One-step growth of perovskite NWs. a, b Slip coating fabrication process of filiform halide perovskite and their optical image. $\mathbf{c}, \mathbf{f}$ Roll-to-roll printing for perovskite NWs thin film. d EISA method to fabricate aligned perovskite NWs. e Selective area deposition of perovskite NWs. $\mathbf{g}$ SEM image of NWs webs. f Transmittance spectra of NWs webs evolved with the precursor concentrations. Inset shows a photograph of semitransparent NWs networks from $30 \mathrm{wt} \%$ concentration. $\mathbf{h}$ Transmittance evolved with OTP precusor concentrations. i, $\mathbf{j}$ Full-inorganic CsPbBr $\mathrm{NW}_{3} \mathrm{NW}_{\mathrm{s}}$ synthesized by onestep method and their typical optical absorption and PL spectra (j). Adapted image reproduced with permission of Ref. [49, 52, 57-59]

like a liquid catalyst cluster model [62]. Time-resolved fluorescence spectroscopy confirmed that charge separation at ETL/perovskite was faster for 1D NWs than for 3D nanocubes, because of the lager surface area of the former structures (Fig. 5c). The conductivity of NW film was enhanced by a factor 1.3-1.6, indicating better connectivity pathways and apparently increased mobility (Fig. 5d).

Similarly, Yang's group replaced the second spin coating step with immersion in $\mathrm{CH}_{3} \mathrm{NH}_{3} \mathrm{Br}$ IPA solution [30]. The lead acetate substrate could support vertical perovskite nanorod arrays (Fig. 5e). The NW absorption onset was at approximately $530 \mathrm{~nm}$ with a bandgap of $2.3 \mathrm{eV}$ [64] (Fig. 5f). The room-temperature $\mathrm{PL}$ of the $\mathrm{CH}_{3} \mathrm{NH}_{3} \mathrm{PbBr}_{3}$ NWs peaked at $534 \mathrm{~nm}$ with a narrow FWHM of $26 \mathrm{~nm}$ under 325-nm HeCd laser excitation (Fig. 5g). The temperature-dependent phases of the $\mathrm{CH}_{3} \mathrm{NH}_{3} \mathrm{PbBr}_{3} \mathrm{NWs}$ underwent multiple phase transitions at 236.3 (to a tetragonal phase), 154.0 (to another tetragonal phase), and $148.8 \mathrm{~K}$ (to an orthorhombic phase), which may account for the observed redshift [65]. In comparison with bulk crystal PL, the $\mathrm{CH}_{3-}$ $\mathrm{NH}_{3} \mathrm{PbBr}_{3}$ nanorod arrays had a $13 \%$ contribution of the fast component to the steady-state PL, which indicated the high quality of the single-crystalline nanorods.

\subsubsection{Chemical Vapor Transport (CVT) Method}

This instrument is the same as a tube furnace for traditional chemical vapor deposition [66]. The reaction sources of $\mathrm{PbX}_{2}$ and $\mathrm{CsX}(X=\mathrm{Cl}, \mathrm{Br}$, or I) powders were placed inside a quartz tube reactor [66]. The Si substrate was positioned at a distance from the source. The temperatures of the powder sources and Si substrate were set at 570-600 and $350-380{ }^{\circ} \mathrm{C}$, respectively. The inert carrier gas was utilized to transport the source vapor for deposition on the 

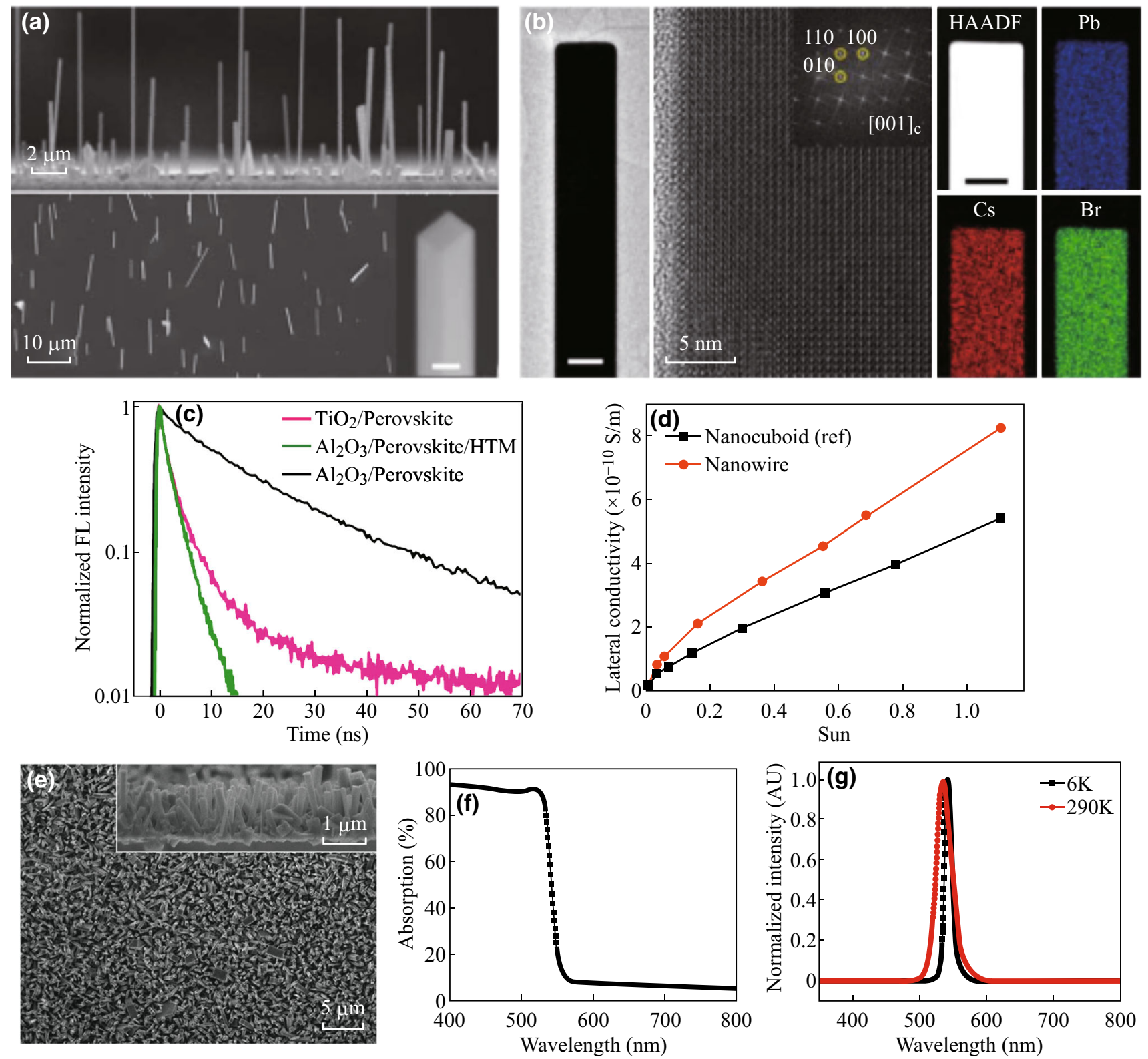

Fig. 5 Two-step method for perovskite NW growth. a SEM images of vertically aligned $\mathrm{CsPbBr}_{3} \mathrm{NWs}_{\mathrm{s}}$ with a rectangular cross section. b HRTEM and FFT images of a $\mathrm{CsPbrr}_{3}$ NWs. $\mathbf{c}$ Fluorescence decay kinetics of $\mathrm{MAPbI}_{3} \mathrm{NWs}_{\mathrm{d}} \mathbf{d}$ Conductivity improvement in the inplane perovskite NWs. e SEM image of $\mathrm{CH}_{3} \mathrm{NH}_{3} \mathrm{PbBr}_{3}$ nanorod array. f, g Typical absorption and PL spectra of $\mathrm{CH}_{3} \mathrm{NH}_{3} \mathrm{PbBr}_{3}$ nanorod arrays. Adapted image reproduced with permission of Ref. [30, 63]

Si substrate (Fig. 5a, b). Apart from the above-mentioned research, Yi-bing Cheng et al. also utilized the CVT method to synthesize perovskite MWs [67].

\subsubsection{Template Method}

According to the lead ionic precursor NWs and the later morphology-retaining reaction, Zhang's group introduced a new lead NW template as the lead source [68]. The reaction between $\mathrm{Pb}\left(\mathrm{NO}_{3}\right)_{2}$ and L-cysteine aqueous solution with the assistance of ethanolamine could yield the $\mathrm{Pb}$ precursor NW templates [69]. The solid hybrid $\mathrm{Pb}$-containing NWs further transformed into porous $\mathrm{CH}_{3} \mathrm{NH}_{3}$ $\mathrm{PbBr}_{3}$ perovskite $\mathrm{NWs}$ by the addition of $\mathrm{CH}_{3} \mathrm{NH}_{3} \mathrm{Br}$ and $\mathrm{HBr}$ 2-propanol solution (Fig. 6a-c).

The traditional universal templates, anodized aluminum oxide (AAO) templates, were also applied for the synthesis of perovskite NWs [70]. Oriented cylindrical nanopores constructed the uniform vertical perovskite nanowire array templates. This method combined the AAO template and perovskite one-step solution method. Perovskite precursor DMF solution filled into the pores of AAO. The following 

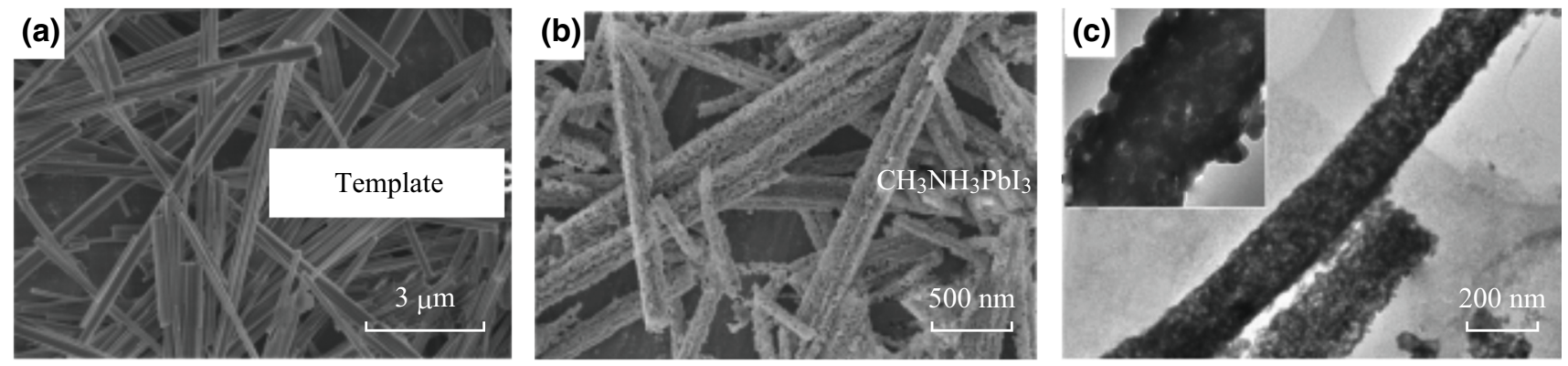
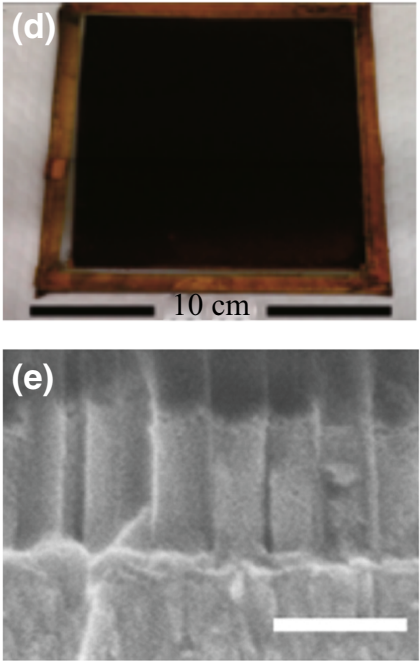
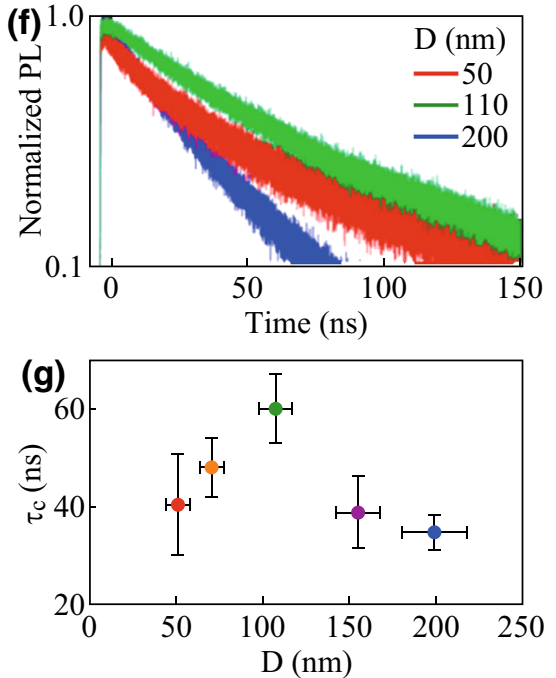
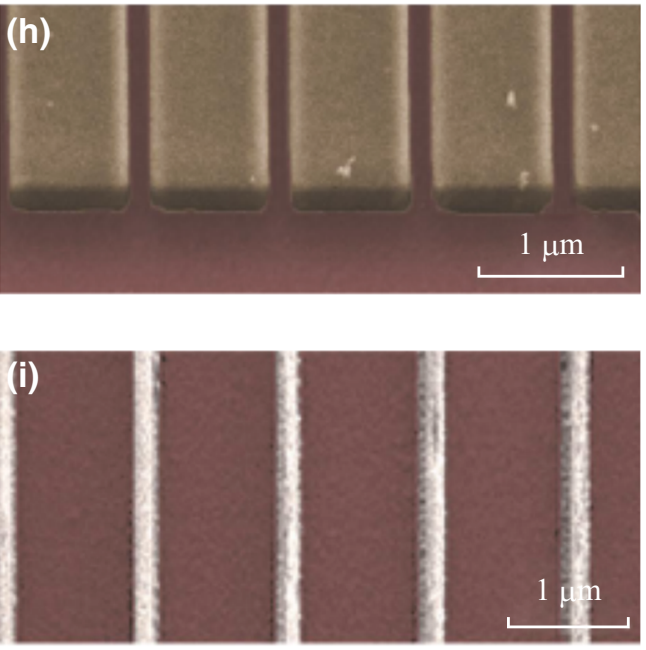

Fig. 6 Template method for perovskite NWs: Pb-containing precursor template a method for perovskite NWs (b, c). AAO template for perovskite NWs. d Photograph of a $\sim 9 \times 9 \mathrm{~cm}^{2}$ NW arrays. e Cross-sectional SEM images of perovskite NWs. Scale bar is $500 \mathrm{~nm}$. f Average $\tau_{\mathrm{c}}$ for different diameter NWs. $\mathbf{g}$ Extension of carrier lifetime as the decrease in NW diameter. $\mathbf{h}$, $\mathbf{i}$ Nanofluidic channel template growth. Adapted image reproduced with permission of Ref. [68, 70, 71]

thermal annealing led to perovskite recrystallization and NW formation at the bottoms of the pores (Fig. 6d, e). The advantage of the present AAO template method is the finetuning of the NW dimensions (diameter and length) by controlling the AAO anodizing recipes [66, 72-74].

Different from the vertical templates, traditional planar electronic fabrication techniques such as photolithography, electron beam lithography could help to fabricate the $1 \mathrm{D}$ channel as the planar growth template. The perovskite NWs were fabricated with the assistance of open nanofluidic channel templates [30] (Fig. 6h, i). The synthesis could be guided and visualized in real time and underwent a metastable solvatomorph formation in polar aprotic solvents. The superior advantages were the precise controlling of sizes, cross-sectional shapes, aspect ratios, and orientations, which had not been achieved by other deposition methods.

\subsection{Two-Dimensional Perovskite}

Two-dimensional (2D) perovskites such as nanosheets, nanoplatelets, and microdisks (MDs) have recently shown high PLQY [75-77]. These 2D perovskites are promising candidates for a variety of applications in nanoelectronics, nanophotonics, and photovoltaics [32, 78]. For instance, Zhao and $\mathrm{Zhu}$ [79] prepared $\mathrm{MAPb}_{2} \mathrm{Br}$ nanosheets with a 1.8-eV bandgap through a thermal decomposition process from a precursor containing $\mathrm{PbI}_{2}, \mathrm{MABr}$, and $\mathrm{MACl}$. The planar solar cells based on the compact layer of $\mathrm{MAPbI}_{2} \mathrm{Br}$ nanosheets achieved a PCE of $\sim 10 \%$.

Xiong's group successfully grew well-defined polygonal $\mathrm{CH}_{3} \mathrm{NH}_{3} \mathrm{PbX}_{3}(X=\mathrm{Cl}, \mathrm{Br}, \mathrm{I})$ nanoplatelets by a chemical vapor method $[24,80]$. As shown in Fig. $7, \mathrm{PbX}_{2}$ platelets were first prepared on muscovite mica using van der Waals epitaxy in a vapor transport chemical deposition system. Subsequently, these $\mathrm{PbX}_{2}$ platelets were placed downstream in a quartz tube to react with MAX vapor by a gassolid heterophase reaction for conversion into perovskite nanoplates. Figure 8 shows the crystal structure and morphologies of perovskite nanoplatelets. Interestingly, the thickness of $\mathrm{PbI}_{2}$ correlated with OIP platelets by a factor of 1.81 , which was in good agreement with their lattice constant ratio along the $c$-axis. This work offers a reliable method to control the thickness of perovskite platelets. 
(a)
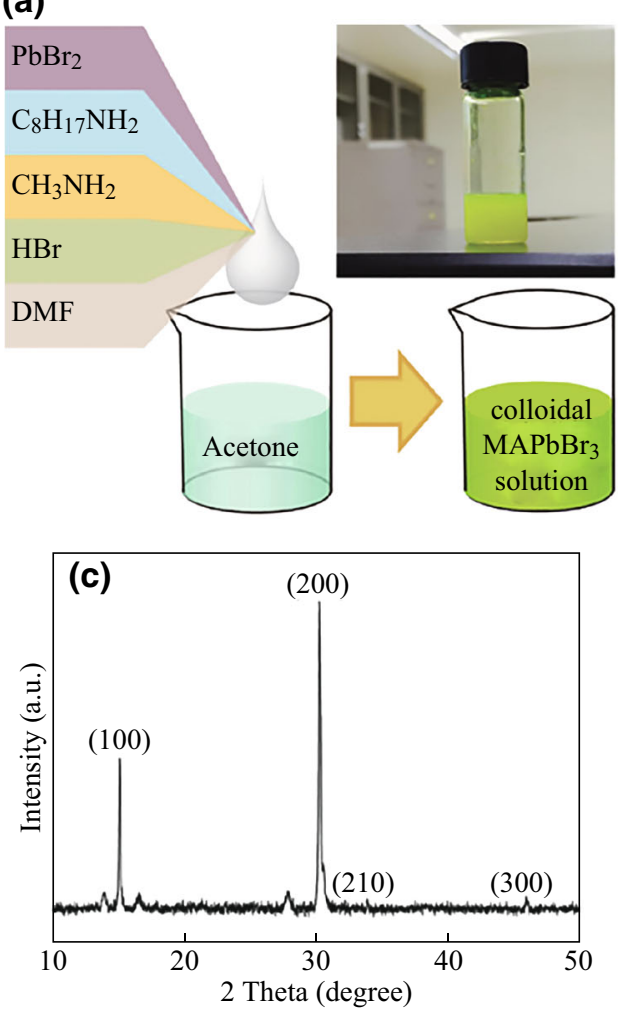
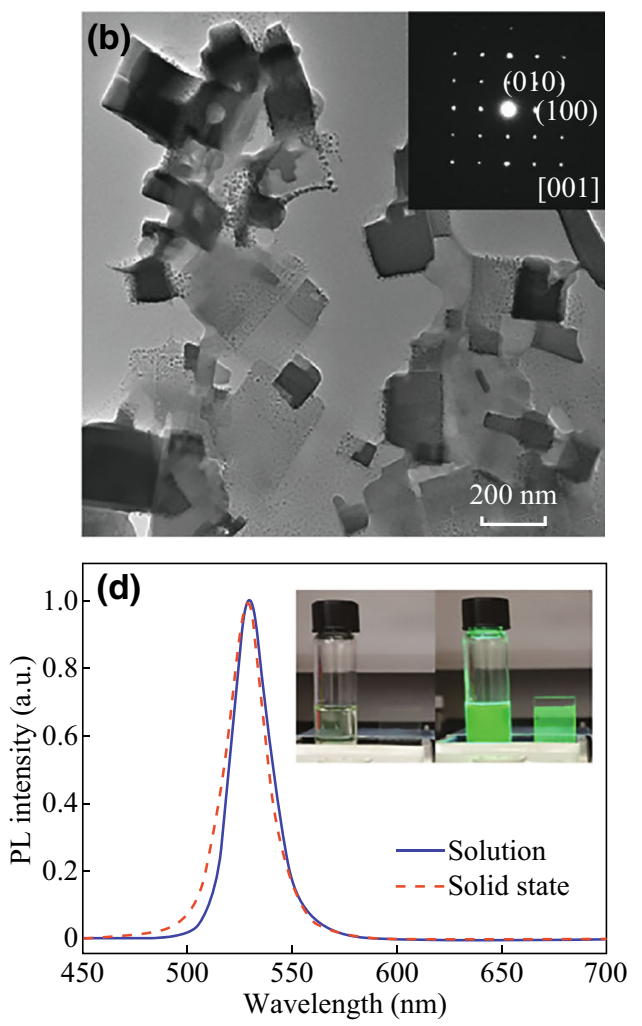

(e)

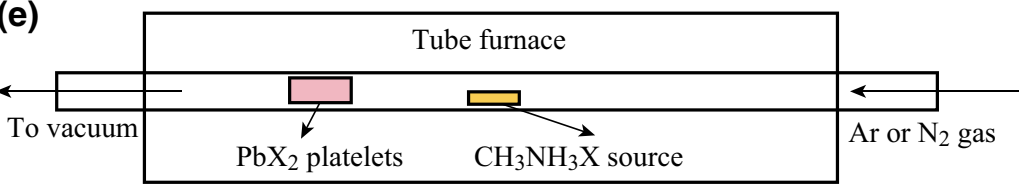

Fig. 7 a Single-crystalline organometal halide perovskite nanoplatelets were synthesized by a one-pot method. Inset is the photograph of the achieved colloidal perovskite nanoplatelet solution. b TEM images and selected area diffraction pattern of $\mathrm{MAPbBr}_{3}$ nanoplatelets. $\mathbf{c} \mathrm{X}$-ray diffraction of $\mathrm{MAPbBr}_{3}$ nanoplatelet film. d PL spectra of $\mathrm{MAPbBr}_{3}$ nanoplatelets in toluene solution and solid state. Inset, the optical images of $\mathrm{MAPbBr}_{3}$ nanoplatelets in toluene solution and in solid-state thin film under ambient light (left) and UV irradiation (right). e Schematic drawing of the nanoplatelet synthesis setup using a home-built vapor transport system. Adapted image reproduced with permission of Ref. [76]

Later, the same group readily applied these perovskite nanoplatelets to fabricate near-infrared solid-state lasers, which exhibited low thresholds and wide mode tunability [24].

Recently, Liao et al. [81] fabricated single-crystalline $\mathrm{CH}_{3} \mathrm{NH}_{3} \mathrm{PbBr}_{3}$ square MDs-based microlasers by using a one-step solution self-assembly method. That approach was similar to anti-solvent vapor-assisted crystallization method [82]. The obtained square MDs had smooth outer surfaces and sharp edges and displayed an absorption peak at $535 \mathrm{~nm}$ and an emission peak at $545 \mathrm{~nm}$. Their four side faces constituted a built-in whispering-gallery mode microresonator with a quality factor as high as 430. By partial replacement of $\mathrm{Br}$ with $\mathrm{Cl}$, the lasing wavelength can be effectively tuned in the green-light range from 525 to $557 \mathrm{~nm}$.

In a more recent study, 2D MAPbBr 3 nanoplatelets with nearly single unit cell thickness and submicron lateral dimensions were prepared by a colloidal synthesis method [29]. Those 2D nanoplatelets exhibited a single and sharp excitonic absorption featured at $431 \mathrm{~nm}$, which blueshifted by $0.5 \mathrm{eV}$ from that of the 3D bulk perovskite phase. This large blueshift was a clear evidence of one-dimensional quantum confinement. A similar colloidal synthetic method was used for full-inorganic $\mathrm{CsPbBr}_{3}$ nanoplatelets (Fig. 9), which exhibited narrow PL and strong excitonic absorption [83]. Recently, Yu et al. demonstrated that the crystallinity of monoclinic $\mathrm{CsPbBr}_{3}$ was much lower than that of tetragonal $\mathrm{CsPb}_{2} \mathrm{Br}_{5}$, and thus, they reported a new type of highly luminescent perovskite-related pure tetragonal $\mathrm{CsPb}_{2} \mathrm{Br}_{5}$ nanoplatelets synthesized by a facile precipitation reaction. Moreover, a new kind of pure phase perovskite nanosheets can be obtained by utilizing cation exchange and anion exchange [84]. In the tetragonal $\mathrm{CsPb}_{2} \mathrm{Br}_{5}$ structure, one layer of Cs ions is sandwiched between two layers of $\mathrm{Pb}-\mathrm{Br}$ coordination polyhedrons, which have an obviously 

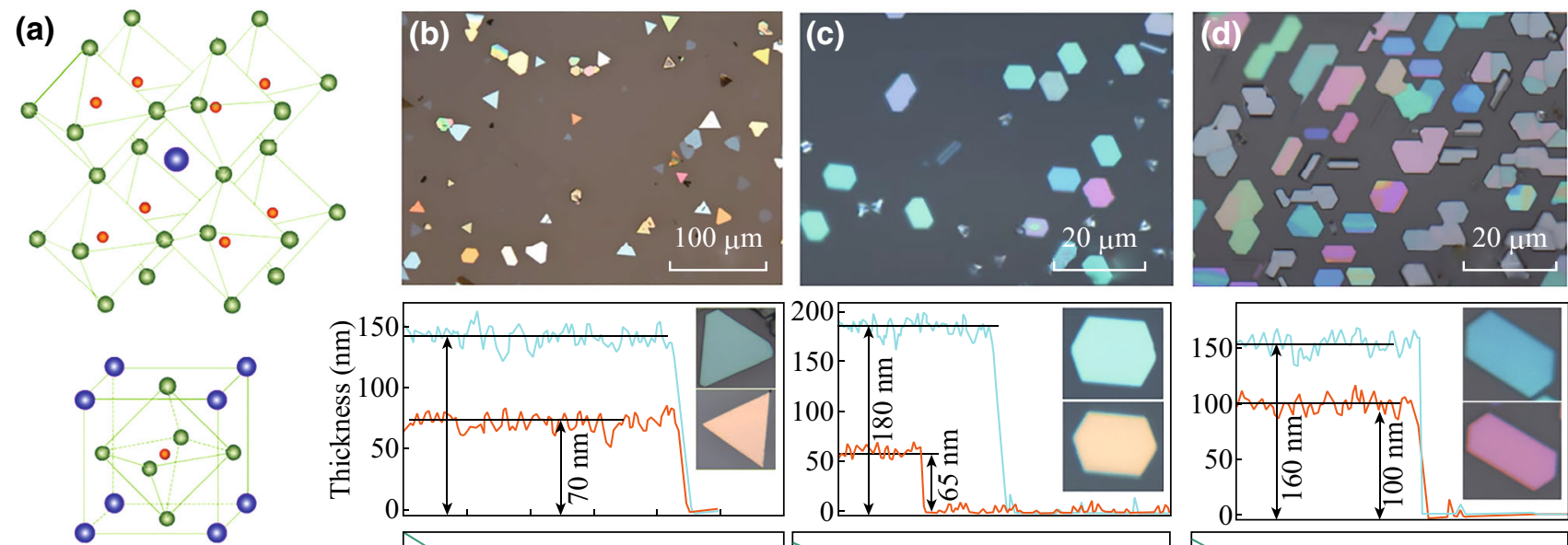

- $\mathrm{CH}_{3} \mathrm{NH}_{3} \odot \mathrm{Pb}$

O I, $\mathrm{Br}$ or $\mathrm{Cl}$
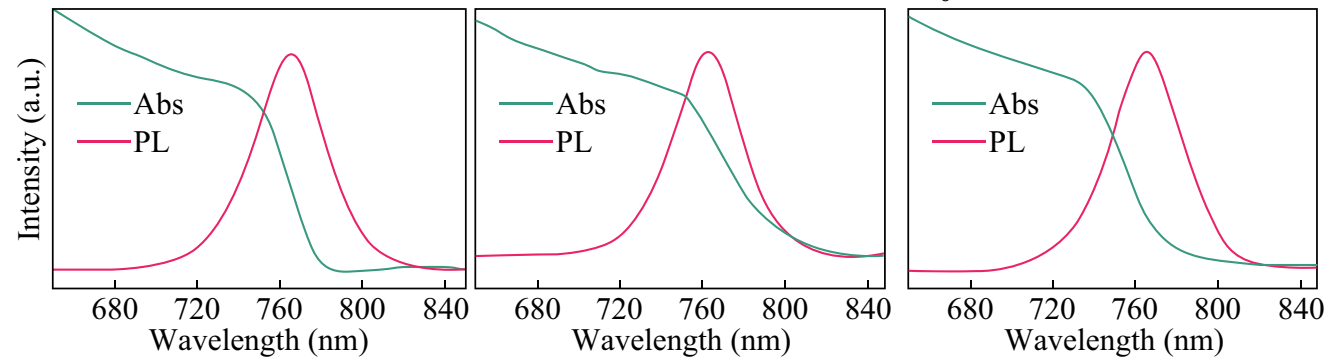

Fig. 8 Chemical vapor-deposited methylammonium lead halide perovskite nanoplatelets. a Schematic figure of crystal structures of $\mathrm{CH}_{3} \mathrm{NH}_{3} \mathrm{PbI}_{3-a} \mathrm{X}_{a}(X=\mathrm{I}, \mathrm{Br}, \mathrm{Cl})$. Morphological and electronic band edge characterizations of $\mathrm{CH}_{3} \mathrm{NH}_{3} \mathrm{PbI}_{3}(\mathbf{b}), \mathrm{CH}_{3} \mathrm{NH}_{3} \mathrm{PbI}_{3-a} \mathrm{Br}_{a}(\mathbf{c})$, and $\mathrm{CH}_{3} \mathrm{NH}_{3} \mathrm{PbI}_{3-a} \mathrm{Cl}_{a}$ (d) nanoplatelets. Adapted image reproduced with permission of Ref. [24]

different crystal structure from the $\mathrm{CsPbBr}_{3}$ perovskite. Jiang et al. synthesized $\mathrm{CsPb}_{2} \mathrm{Br}_{5}$ nanosheets by using a solution-phase method. They found that the tetragonal $\mathrm{CsPb}_{2} \mathrm{Br}_{5}$ nanosheets were formed via an oriented attachment of $\mathrm{CsPbBr}_{3}$ nanocubes with an orthorhombic structure [85]. Jang et al. [86] synthesized $\mathrm{MAPbBr}_{3}$ nanoplates using octylamine as the capping ligand. The composition of nanoplates was tunable by a simple halide exchange reaction. Furthermore, Yang et al. reported the solution growth of atomically thin, uniform, and square-shaped 2D hybrid perovskites of $\left(\mathrm{C}_{4} \mathrm{H}_{9} \mathrm{NH}_{3}\right)_{2} \mathrm{PbBr}_{4}$ [87]. Different from conventional 2D materials, the $\left(\mathrm{C}_{4} \mathrm{H}_{9} \mathrm{NH}_{3}\right)_{2} \mathrm{PbBr}_{4}$ sheet exhibited an unusual lattice constant expansion, which led to a slightly shifted band edge emission relative to the bulk counterpart. Those 2D crystals also displayed high PL quantum efficiency and color tunability through halide substitution and thickness variation.

It is interesting to note that perovskite nanosheets were surprisingly obtained from electrospraying the precursor solution into a mixed bath of toluene (as anti-solvent) and oleylamine (for intercalation) [88]. Recently, single crystals of OIP nanoplates with well-defined facets were grown via a dissolution-recrystallization path from $\mathrm{PbI}_{2}$ (or $\mathrm{PbAc}_{2}$ ) films [89]. These 2D perovskite nanostructures displayed strong room-temperature PL and long carrier lifetime.

\section{Low-Dimensional Perovskite Optoelectronic Applications}

\subsection{Light-Emitting Diodes}

The key parameter for high-performance light-emitting materials is the PLQY, defined as the ratio of emitted to absorbed photons. On the LED level, the radiant efficiency (RE) or wall plug efficiency (WPE) is the electrical-tooptical energy conversion efficiency described as:

$$
\begin{aligned}
\mathrm{RE}(\text { or } \mathrm{WPE}) & =\mathrm{EQE} \times \mathrm{LE} \\
& =\eta_{\text {injection }} \times \mathrm{IQE} \times \eta_{\text {extraction }} \times(L / I V),
\end{aligned}
$$

where the external quantum efficiency (EQE) is defined as the ratio of emitted photons to the number of electrons injected into the device and the luminous efficacy (LE) is the ratio of emitted photons to the energy injected by the source $(I V)$. The ultralow amplified spontaneous emission (ASE) thresholds of organometallic halide perovskites provide a strong impetus for light-emission applications. 

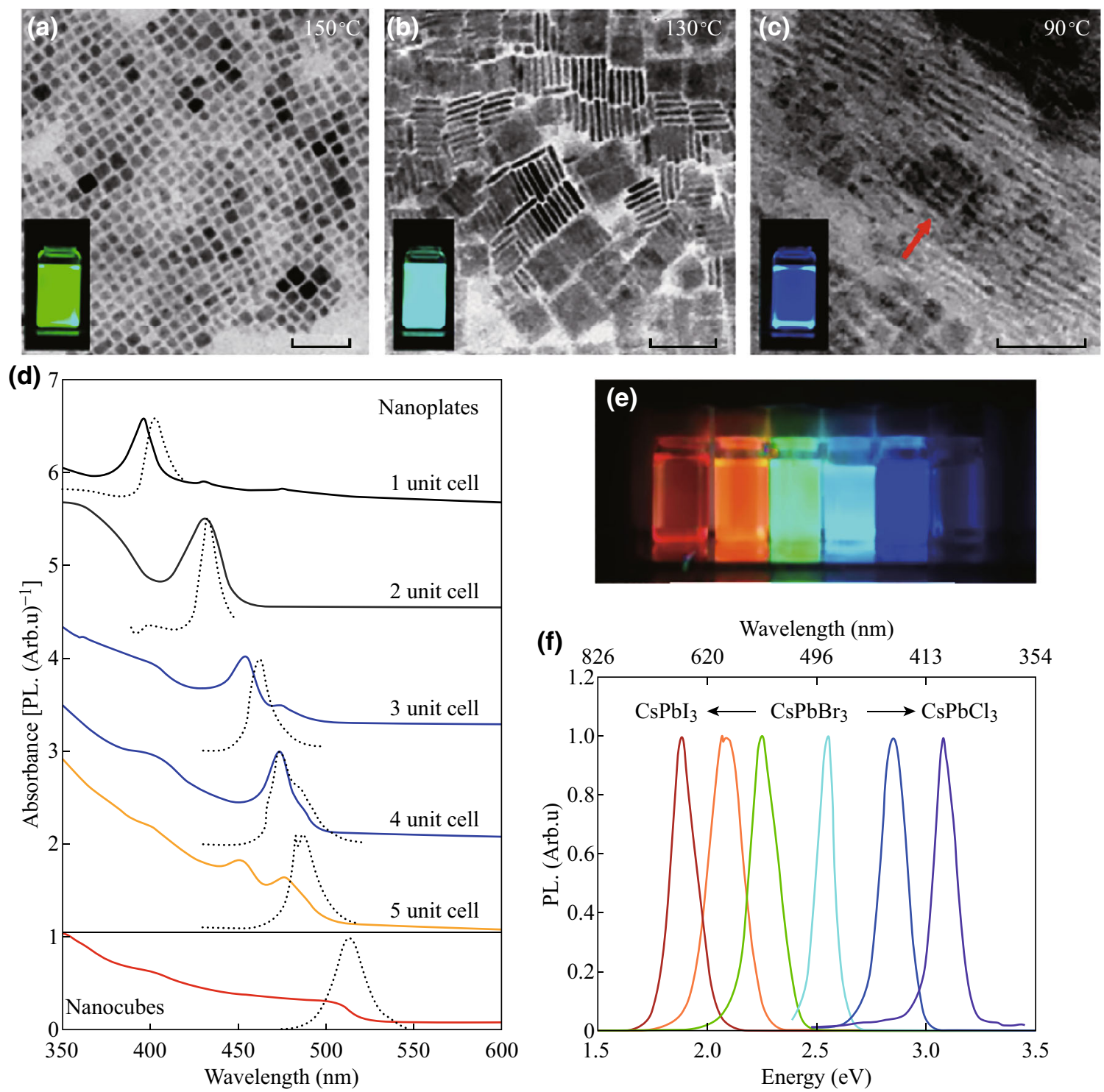

Fig. 9 Reaction temperature influence on colloidal $\mathrm{CsPbBr}_{3}$ synthesis. 8- to 10 -nm nanocubes were formed at $150{ }^{\circ} \mathrm{C}(\mathbf{a}), 20-\mathrm{nm}$ nanoplates from $130{ }^{\circ} \mathrm{C}$ (b) reaction and $90{ }^{\circ} \mathrm{C}$, c reaction yielded several hundred nanometer scale lamellar nanostructures. Scale bar is $50 \mathrm{~nm}$. d Absorption (solid lines) and emission (dashed lines) spectra of NPLs and nanocubes for comparison. e Colloidal solution of anion-exchanged NPLs in hexane under UV illumination $(\lambda=365 \mathrm{~nm})$. f Inorganic perovskite PL peaks evolved with their anions. Adapted image reproduced with permission of Ref. [75]

The extraordinary enhancement of the PLQY in the past 2 years has now placed perovskites on a par with the best-inclass solution-processed semiconductors. Different strategies, such as synthesis of low-dimensional layered perovskites, or increasing spatial confinement, have been applied to maximize PLQYs. The high PLQYs combined with the compositional flexibility of these materials render perovskites robust technological candidates. They are distinguished by: (1) high color purity (FWHM $20 \mathrm{~nm}$ ) [37] (Fig. 10), irrespective of the crystallite size [32, 91]; (2) bandgap tunability covering the entire spectrum of visible light in layered perovskites [92, 93]; and (3) low to moderate ionization energy to form stable functional interfaces [94].
Organic-inorganic lead-based perovskites were first investigated for light-emitting applications before they were used as absorbers in DSSC devices. Perovskite LEDs were first demonstrated in the 1990s using organic-inorganic perovskites with layered two-dimensional structures. However, electroluminescence from radiative recombination of injected electrons and holes was only observed at liquid nitrogen temperatures. Recently, perovskite lightemitting diodes (PeLEDs) of the low-dimensional metal halide perovskites $\mathrm{MAPbI}_{3-x} \mathrm{Cl}_{x}, \quad \mathrm{MAPbBr}_{3}$, and $\mathrm{MAPbI}_{3-x} \mathrm{Br}_{x}$ have been demonstrated. These devices operated at room temperature under substantial current densities and brightness. The internal quantum efficiencies 

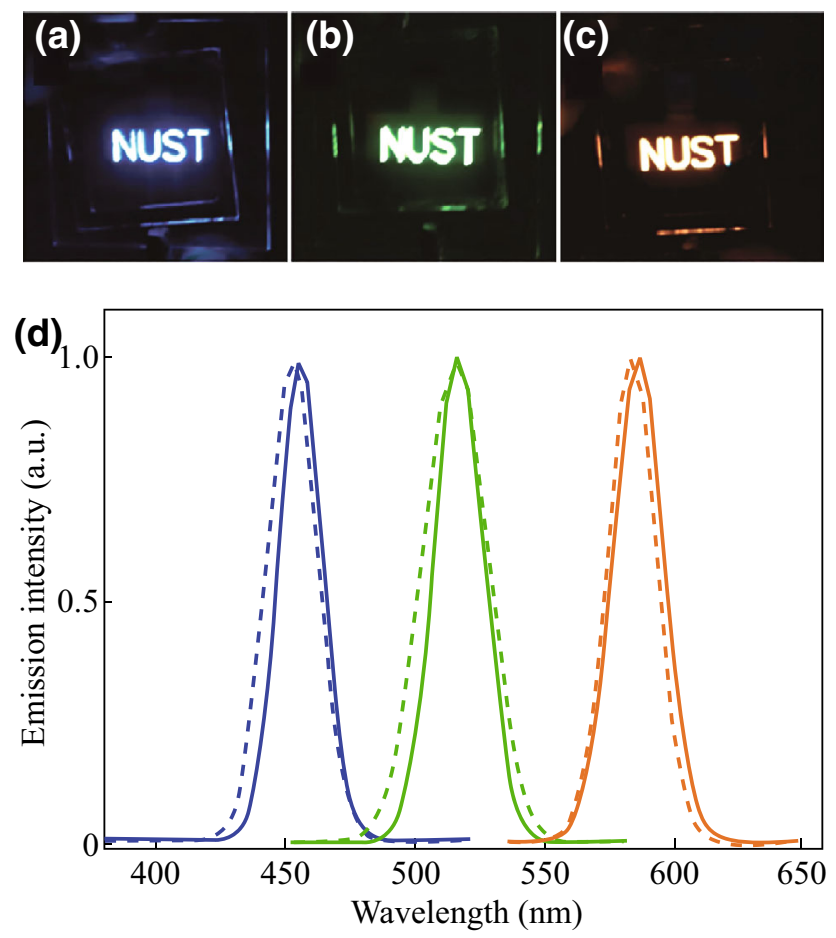

Fig. 10 a-c Emissions of QLED devices utilizing different QD sizes. d The EL (solid line) and the PL spectra (dashed line) of samples shown in $(\mathbf{a}-\mathbf{c})$. e CIE coordinates of the three color QLEDs (circular) compared to the NTSC color standards (star). Adapted image reproduced with permission of Ref. [90]

reached $3.4 \%$, and the emissions were located at near-infrared and green (Fig. 11). Comparable emission has also been demonstrated in an inverted structure by tuning the work function of the conventional PEDOT:PSS hole injection layer. However, the above two devices require high charge densities for efficient radiative recombination. Enhanced device emission and quantum efficiency would be obtained by removing or filling material trap states and optimizing film quality, similar to halide perovskite solar cells.

In addition to possessing maximal external luminescence, a good light-emitting device requires efficient carrier injection and radiative recombination. In particular, balancing the electron and hole injection by tailoring the interfaces helps to focus the radiative recombination within the desired emitter layer. In this respect, metal halide perovskites can meet the charge transport and charge injection requirements with high carrier mobility and optimum interface formation with most employed contacts. In PeLEDs, the emitter layer may comprise 3D, layered, or nanostructured perovskites sandwiched between electron and hole transport layers (Fig. 12). The EQE of PeLEDs has rapidly progressed from less than $1 \%$ to over $8 \%$ in fewer than 2 years. In addition, the $\mathrm{CE}$ and luminance are approaching the QLED and OLED top ranges. Tae-Woo

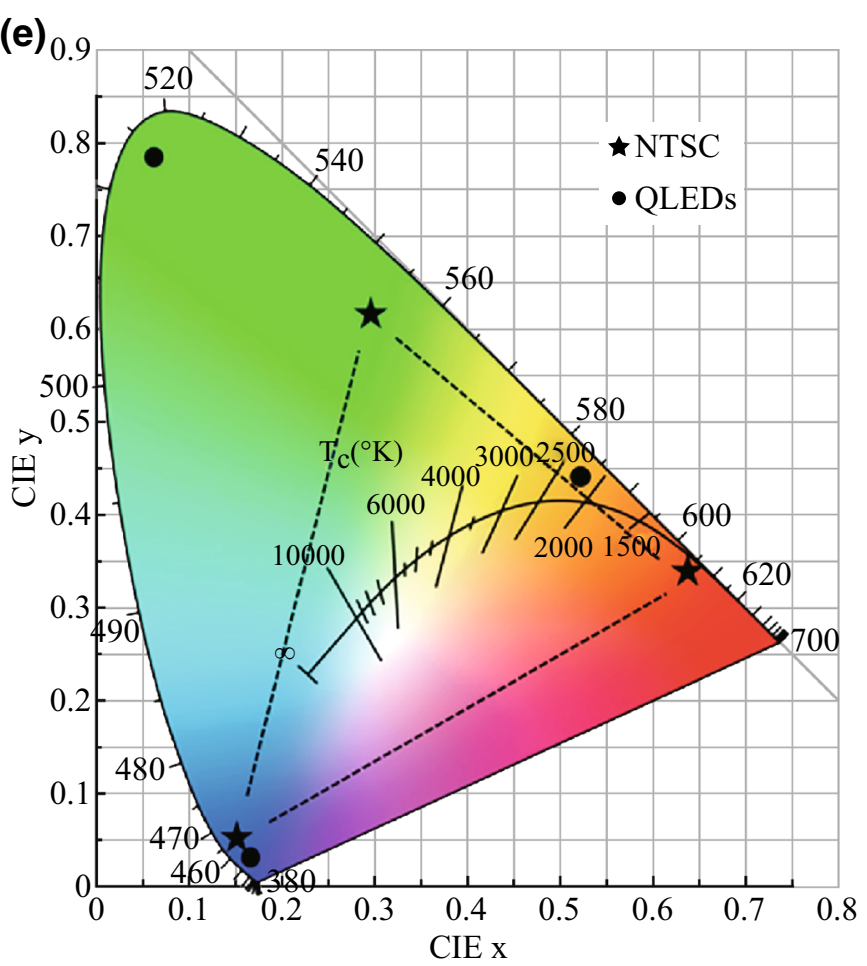


(a)
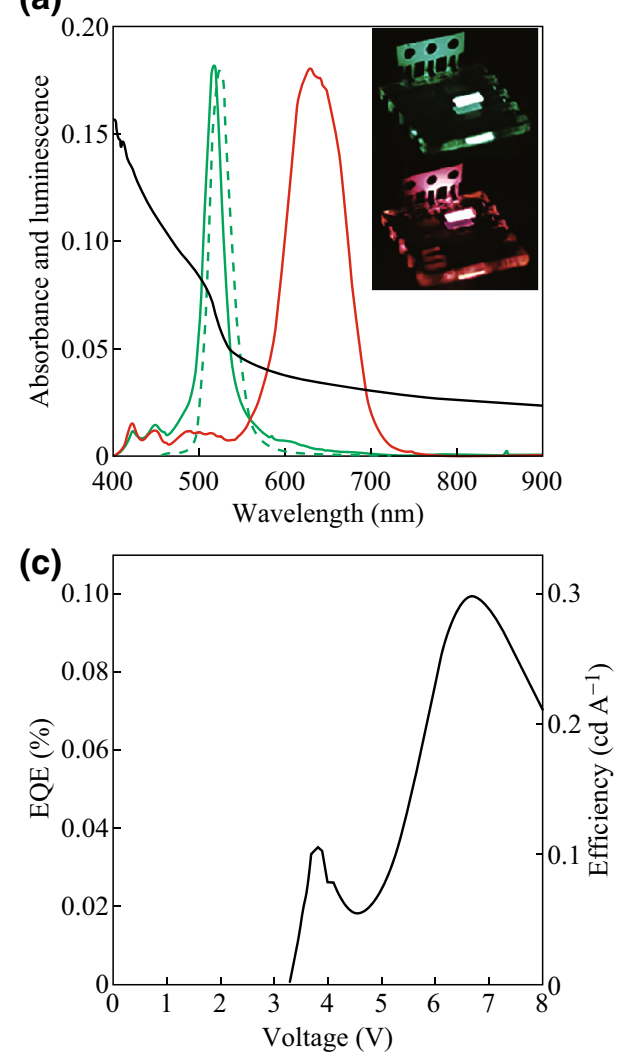

(b)
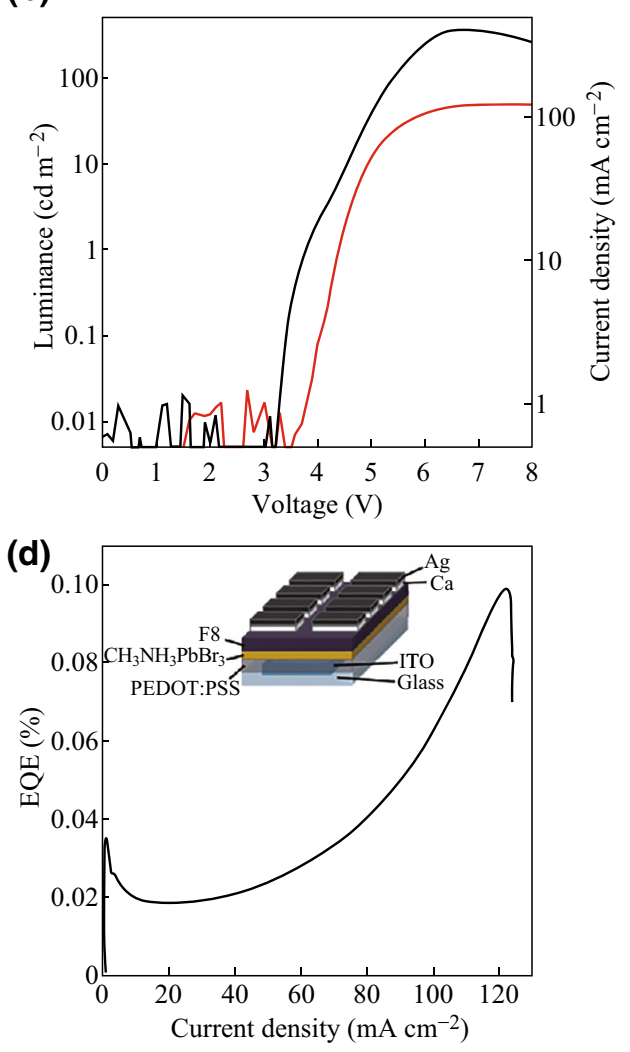

Fig. 11 Device characteristics of visible PeLEDs. a Absorption (black), normalized EL (solid line in green), and PL (dashed line in green) spectra of $\mathrm{CH}_{3} \mathrm{NH}_{3} \mathrm{PbBr}_{3}$ perovskite. EL spectrum of mixed halide perovskite is shown in red. b Luminance (black) and current density (red) versus voltage characteristics of the green PeLED. $\mathbf{c}$ EQE versus voltage characteristics of the green PeLED. $\mathbf{d}$ EQE versus current density of the green PeLED. Adapted image reproduced with permission of Ref. [96]. (Color figure online)
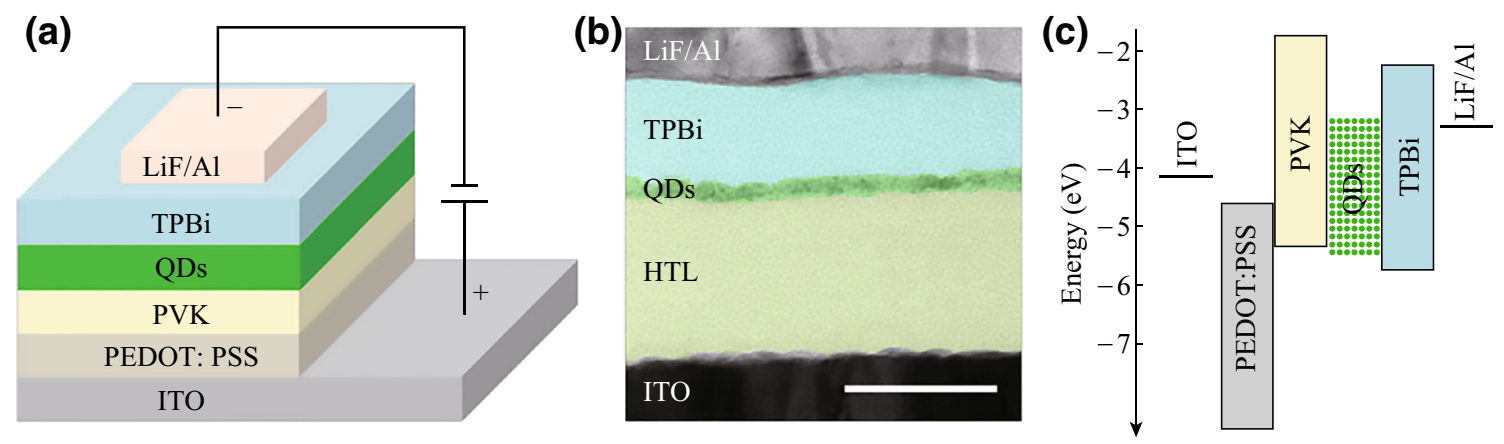

Fig. 12 Illustration of multilayer PeLED device. a Device structure. b Cross-sectional TEM image of multiple layers with distinct contrast. Scale bar is $50 \mathrm{~nm}$. c Flat-band energy level diagram. Adapted image reproduced with permission of Ref. [90]

because of the thicker film required to avoid shorting of the inter-NWs void. However, for specific fields, the non-full fill of substrate by NWs may find suitable applications such as semitransparent solar cells, building-integrated photovoltaics. The elementary results were greatly improved by the group of Nam-Gyu Park [63]. In order to avoid the void-induced shorting effect, they developed a two-step method to grow denser and smaller-diameter NWs as the absorber (Fig. 13c, d). Perovskite NWs with a mean diameter of $100 \mathrm{~nm}$ showed faster carrier separation in the presence of the hole-transporting layer and higher lateral conductivity than their 3D counterparts. The best performing device exhibited a photocurrent density of $19.12 \mathrm{Ma} \mathrm{cm}^{-2}$, voltage of $1.052 \mathrm{~V}$, and fill factor of 0.721 , leading to a PCE of $14.71 \%$ with small $I-V$ hysteresis (Fig. 13e, f). 
Table 1 Overview of selected representative results of PeLED [36, 76, 88-93, 95]

\begin{tabular}{|c|c|c|c|c|c|c|c|}
\hline Perovskite emitter & Morphology & Device architecture & EQE $(\%)$ & $\mathrm{CE}\left(\mathrm{cd} \mathrm{A}^{2}\right)$ & $\begin{array}{l}\mathrm{L}_{\max } \\
\left(\mathrm{cd} \mathrm{m}^{-2}\right)\end{array}$ & $\begin{array}{l}\mathrm{Vr} \\
(\mathrm{V})\end{array}$ & $\begin{array}{l}\text { Publication } \\
\text { date (month- } \\
\text { year) }\end{array}$ \\
\hline $\mathrm{CH}_{3} \mathrm{NH}_{3} \mathrm{PbBr}_{3}$ & Thin film & ITO/PEDOT:PSS/Pe/F8/Ca/Ag & 0.1 & 0.3 & 364 & 3.3 & 08-2014 \\
\hline $\mathrm{CH}_{3} \mathrm{NH}_{3} \mathrm{PbBr}_{3}$ & Thin film & ITO/Buf HIL/Pe/TPBI/LiF/Al & 0.125 & 0.57 & 417 & $\sim 4$ & $11-2014$ \\
\hline $\mathrm{CH}_{3} \mathrm{NH}_{3} \mathrm{PbBr}_{3}$ & Thin film & ITO/PEDOT:PSS/TPD/Pe/Ag & $6.5 \times 10^{-3}$ & $\sim 1.8 \times 10^{-2}$ & 21 & 4 & 01-2015 \\
\hline $\mathrm{CH}_{3} \mathrm{NH}_{3} \mathrm{~Pb}_{3-x} \mathrm{Br}_{x}$ & Thin film & ITO/PEDOT:PSS/TPD/Pe/Ag & $1.1 \times 10^{-3}$ & n.r & n.r & n.r & $01-2015$ \\
\hline $\mathrm{CH}_{3} \mathrm{NH}_{3} \mathrm{PbBr}_{3}$ & Thin film & ITO/PEDOT:PSS/Pe/ZnO/Ca/Ag & n.r. & $\sim 21$ & $\sim 550$ & 2 & $02-2015$ \\
\hline $\mathrm{CH}_{3} \mathrm{NH}_{3} \mathrm{PbBr}_{3}$ & Thin film & $\begin{array}{l}\text { ITO/PEDOT:PSS/Pe-PIP/F8/Ca/ } \\
\text { Ag }\end{array}$ & 1.2 & n.r & 200 & n.r & 04-2015 \\
\hline $\mathrm{CH}_{3} \mathrm{NH}_{3} \mathrm{PbBr}_{3}$ & Thin film & ITO/ZnO-PEI/Pe/TFB/MoO $/ \mathrm{Au}$ & 0.8 & n.r & 20,000 & 2.8 & $04-2015$ \\
\hline $\mathrm{CH}_{3} \mathrm{NH}_{3} \mathrm{~Pb}_{3-x} \mathrm{Cl}_{x}(\mathrm{red})$ & Thin film & ITO/ZnO-PEI/Pe/TFB/MoO $/ \mathrm{Au}$ & 3.5 & n.r & n.r & 2.2 & 05-2015 \\
\hline $\mathrm{CH}_{3} \mathrm{NH}_{3} \mathrm{~Pb}_{3-x} \mathrm{Cl}_{x}(\mathrm{red})$ & Thin film & $\mathrm{FTO} / \mathrm{TiO}_{2} / \mathrm{Pe} / \mathrm{Spiro}-\mathrm{MeTAD} / \mathrm{Au}$ & 0.48 & n.r & n.r & 1.5 & $05-2015$ \\
\hline $\mathrm{CH}_{3} \mathrm{NH}_{3} \mathrm{PbBr}_{3}$ & Thin film & $\begin{array}{l}\mathrm{ITO} / \mathrm{c}_{-} \mathrm{TiO}_{2} / \mathrm{EA} / \mathrm{Pe} / \mathrm{SPB}-02 \mathrm{~T} / \\
\mathrm{MoO}_{x} / \mathrm{Au}\end{array}$ & 0.051 & 0.22 & 545 & n.r & $07-2015$ \\
\hline $\mathrm{CH}_{3} \mathrm{NH}_{3} \mathrm{~Pb}_{3-x} \mathrm{Cl}_{x}$ & Thin film & ITO/Mg-ZnO/Pe/CBP/MoO $/ \mathrm{Au}$ & 0.1 & n.r & n.r & 2.2 & 08-2015 \\
\hline $\mathrm{CH}_{3} \mathrm{NH}_{3} \mathrm{PbBr}_{3}$ & Thin film & ITO/Pe-PEO/In-Ga & 0.083 & 0.38 & 4064 & 2.9 & $10-2015$ \\
\hline $\mathrm{CsPbBr}_{3}$ & QD & $\begin{array}{l}\text { ITO/PEDOT:PSS/PVK/Pe/TPBI/ } \\
\text { LiF-Al }\end{array}$ & 0.12 & 0.43 & 946 & 4.2 & $10-2015$ \\
\hline $\mathrm{CsPbBr}_{3}$ & Thin film & ITO/PEDOT:PSS/Pe/F8/Ca/Ag & 0.008 & 0.035 & 407 & 3 & $11-2015$ \\
\hline $\mathrm{CH}_{3} \mathrm{NH}_{3} \mathrm{PbBr}_{3}$ & Thin film & $\begin{array}{l}\text { ITO/PEDOT:PSS/Pe/SPB-02T/ } \\
\text { LiF/Al }\end{array}$ & 0.1 & 0.43 & 3490 & 2.4 & $11-2015$ \\
\hline $\mathrm{CH}_{3} \mathrm{NH}_{3} \mathrm{PbBr}_{3}$ & NPLs & $\begin{array}{l}\text { ITO/PEDOT:PSS/Pe/PVK:PBD/ } \\
\text { BCP/LiF/Al }\end{array}$ & 0.48 & n.r & 10590 & 3.8 & $11-2015$ \\
\hline $\mathrm{CH}_{3} \mathrm{NH}_{3} \mathrm{PbBr}_{3}$ & Thin film & $\begin{array}{l}\text { ITO/PEDOT:PSS/Pe }(6 \% \mathrm{HBr}) / \\
\text { SPB-02T/LiF/Ag }\end{array}$ & 0.2 & 0.43 & 3490 & 4.3 & $11-2015$ \\
\hline $\mathrm{CH}_{3} \mathrm{NH}_{3} \mathrm{PbBr}_{3}$ & Thin film & Glass/SOCP/Pe/TPBI/LiF-Al & 8.53 & 42.9 & $\sim 15,000$ & 4 & $12-2015$ \\
\hline $\mathrm{CH}_{3} \mathrm{NH}_{3} \mathrm{PbBr}_{3}$ & $\begin{array}{l}\text { Printed thin } \\
\text { film }\end{array}$ & ITO/Pe-PEO/Ag NWs & 1.1 & 4.91 & 21,014 & 2.6 & $12-2015$ \\
\hline
\end{tabular}

All perovskites display green emission unless specially stating

Pe, perovskite; ITO, In-doped $\mathrm{SnO}_{2}$; PEDOT:PSS, poly(3,4-ethylenedioxythiophene):polystyrene sulfonate; F8, poly(9,9-dioctylfluorene); BuffHIL, buffered hole injection layer; TPBI, 2,2',2' -(1,3,5-benzinetriyl)-tris(1-phenyl-1-H-benzimidazole); TPD, $N, N^{\prime}$-bis(3- methylphenyl)- $N, N^{\prime}$ diphenylbenzidine); PIP, polyimide polymer; PEI, poly(ethylenimine), TFB, poly(9,9-dioctylfluorene-co- $N$-(4-butylphenyl)diphenylamine); EA, ethanolamine; SPB-02T, blue copolymer, Merck Co.; BCP, bathocuproine; PEO, poly(ethyleneoxide); PVK, poly(9-vinlycarbazole); PBD, 2-(4-biphenylyl)-5-phenyl-1,3,4- oxadiazole; n.r, Not reported

There are many reviews discussing about halide perovskite thin-film solar cells. Thus, we only list the key breakthroughs in chronological order. Miyasaka and coworkers were the first to report $\mathrm{CH}_{3} \mathrm{NH}_{3} \mathrm{PbBr}_{3}$ solar cells with a PCE of $2.2 \%$ in 2006 [98]. In 2009, they improved the PCE to $3.8 \%$ by replacing bromine with iodine. Subsequently, Park and colleagues optimized a titania surface and substituted DMF solvent by $\gamma$-butyrolactone, yielding an efficiency of triiodide cells to $6.5 \%$ in 2011 [14]. Unfortunately, the device stability had not significantly improved. Until 2012, Kanatzidis and coworkers utilized the $p$-type solution-processable perovskite fluorine-doped $\mathrm{CsSnI}_{3}$ as a solid HTL in a solidstate DSSC [99]. This was the first time that a perovskite material has been used as the HTL with efficiencies up to $10.2 \%$. The real breakthrough of perovskite stability was obtained by the Gratzel and Park groups [5]. They utilized $\mathrm{MAPbI}_{3}$ as a light harvester combined with the solid hole conductor $2,2^{\prime}, 7,7^{\prime}$, tetrakis( $N, N$-dimethoxyphenyl-amine)-9,9'-spirobifluorene (spiro-MeOTAD) on mesoporous $\mathrm{TiO}_{2}$ leading to a PCE of $9.7 \%$ and dramatically improving the device stability compared to $\mathrm{CH}_{3} \mathrm{NH}_{3} \mathrm{PbI}_{3}$-sensitized liquid junction cells. From the above-mentioned research [5, 99], it can be concluded that OIP had the excellent capability to achieve ambipolar charge transport. At the same time, a significant study reported by Seok, M. Gratzel, and coworkers [100] boosted the PCE to $12 \%$.

In the middle of 2013, there were two important reports published in the journal Nature, which accelerated the study of perovskite solar cells to a new level $[4,16]$. Both of them had achieved the PCE over $15 \%$ by using new, modified perovskite processing methods. One defined as "sequential deposition" produces a device structure of 


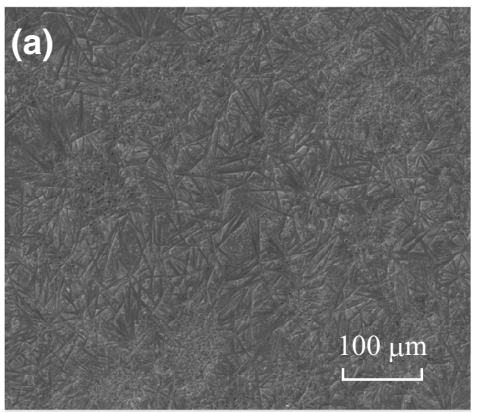

(b)
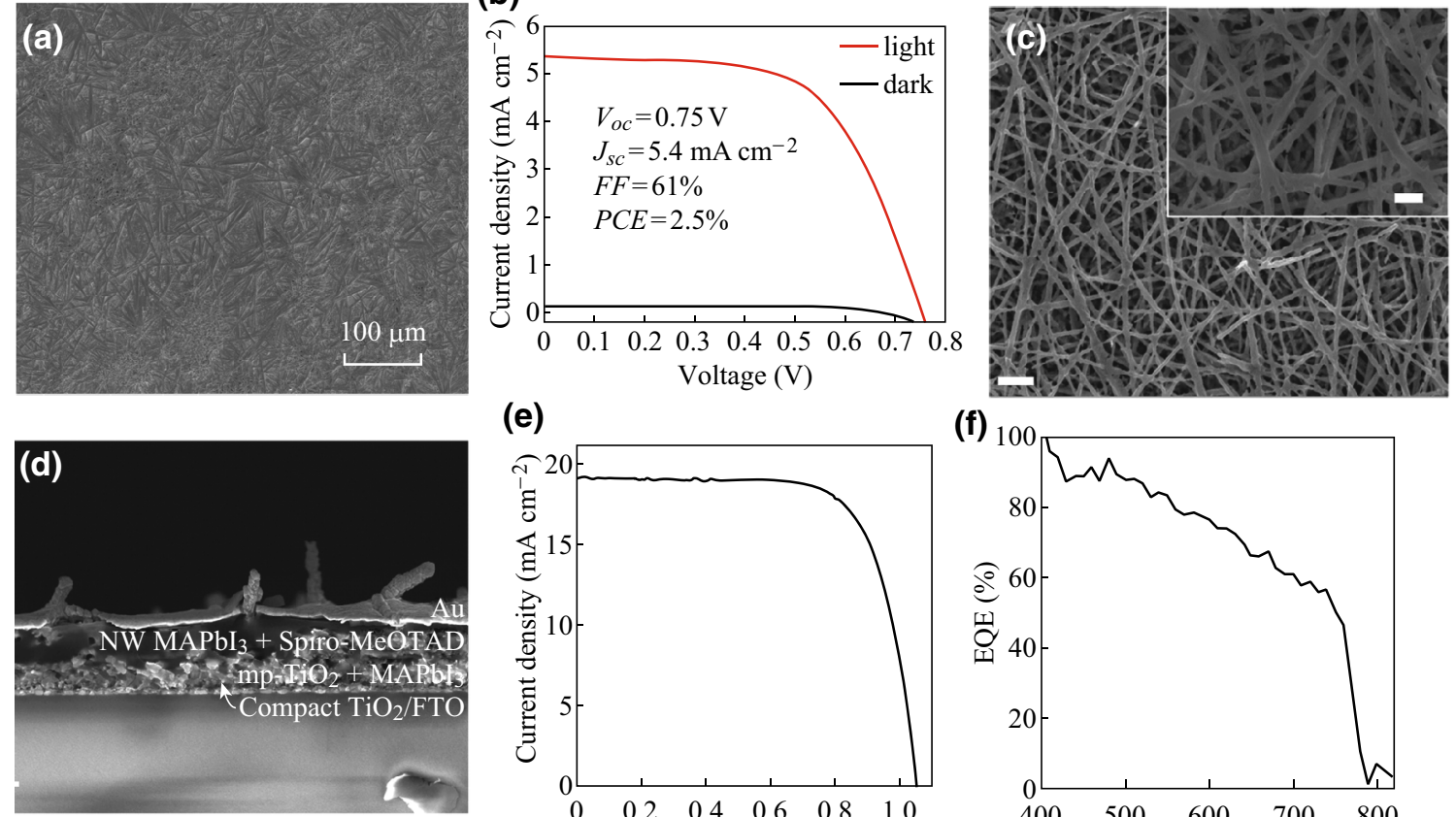

(e)

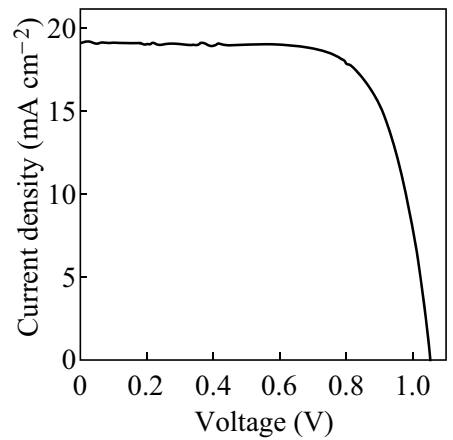

(f)

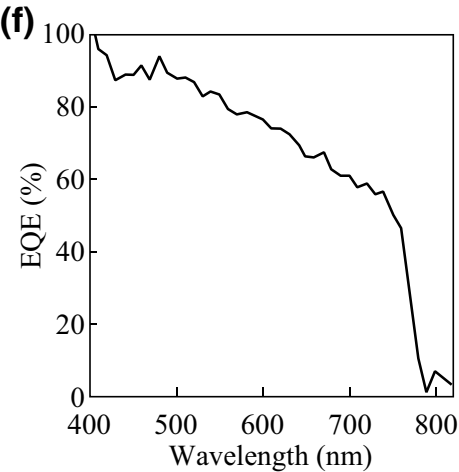

Fig. 13 Perovskite NW solar cells: a, b SEM image of NWs from a one-step method and its corresponding $J-V$ curve. Two-step-method-grown NWs and corresponding device performances. c, $\mathbf{d}$ Top-view and cross section of NWs films. e, $\mathbf{f} J-V$ and IPCE curves of NW solar cells. The scale bar is $1 \mu \mathrm{m}$. Adapted image reproduced with permission of Ref. [52, 63]
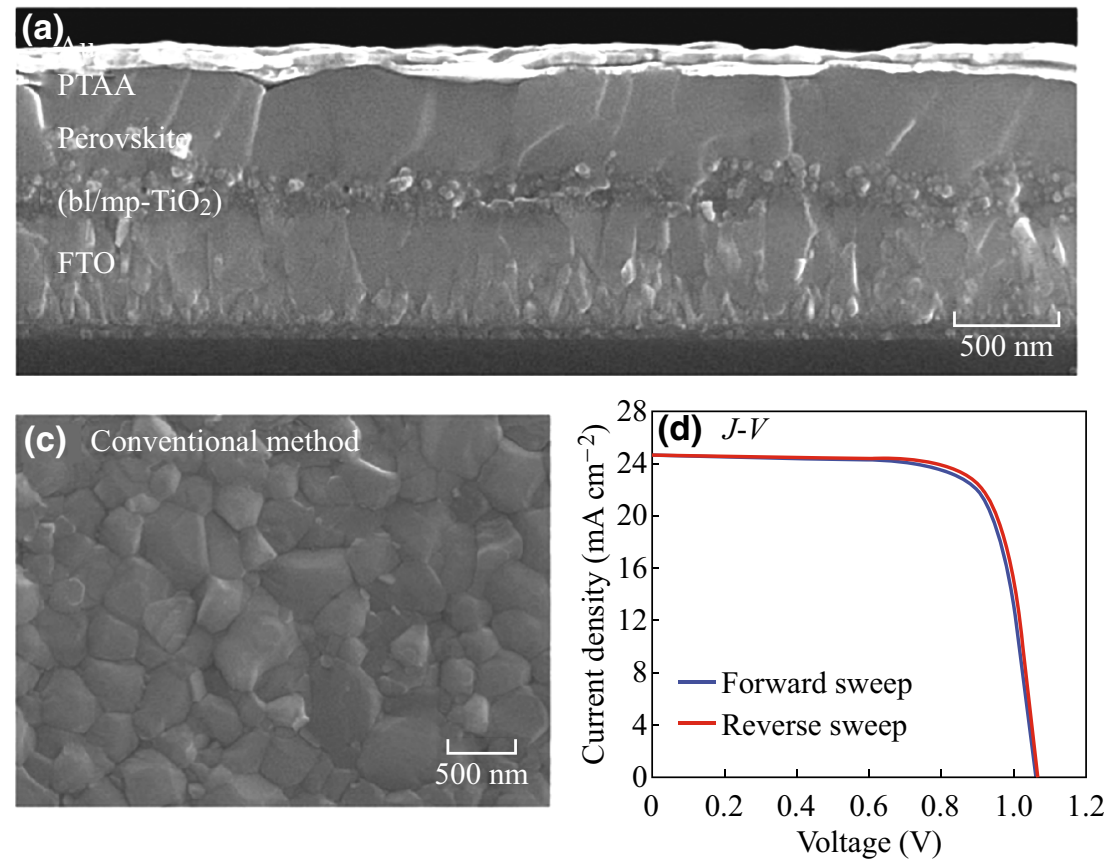
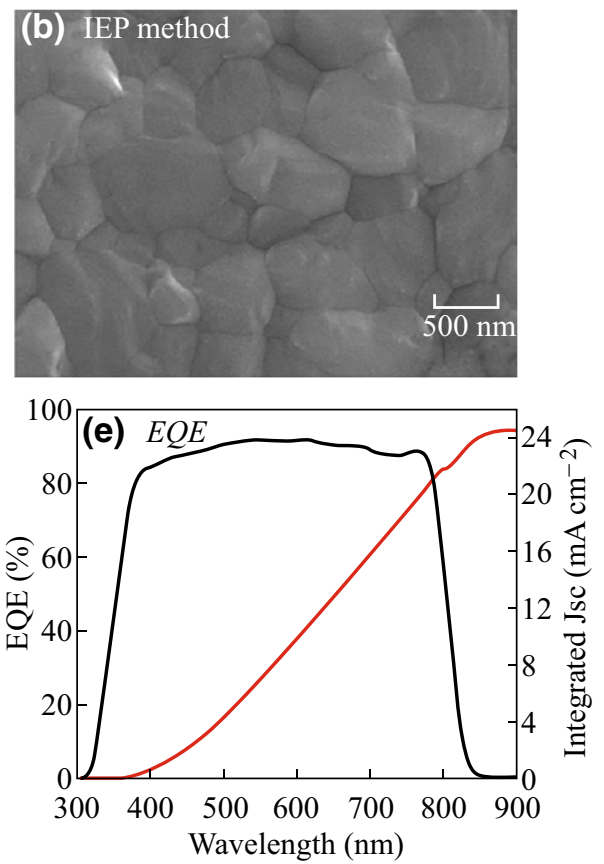

Fig. 14 SEM, $J-V$, and EQE measurements for perovskite solar cells. a Cross-sectional SEM image of the device. The comparison of SEM surface images of $\mathrm{FAPbI}_{3}$-based layer formed on $\mathrm{mp}-\mathrm{TiO}_{2}$ by IEP (b) and conventional method $(\mathbf{c})$. d $J-V$ curves of best device measured in reverse and forward modes, and e EQE spectra for best device and integrated $J_{\mathrm{SC}}$. Adapted image reproduced with permission of Ref. [101] 
(a)

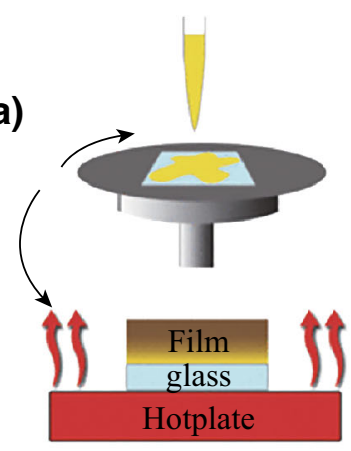

(c)

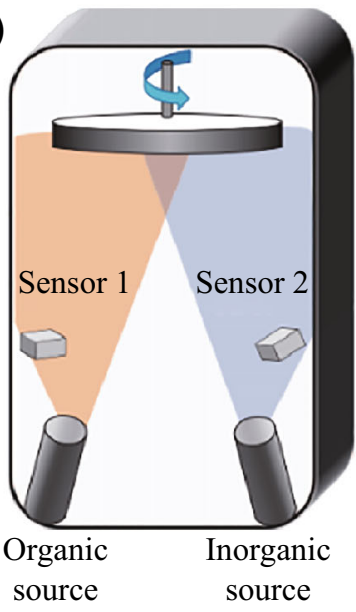

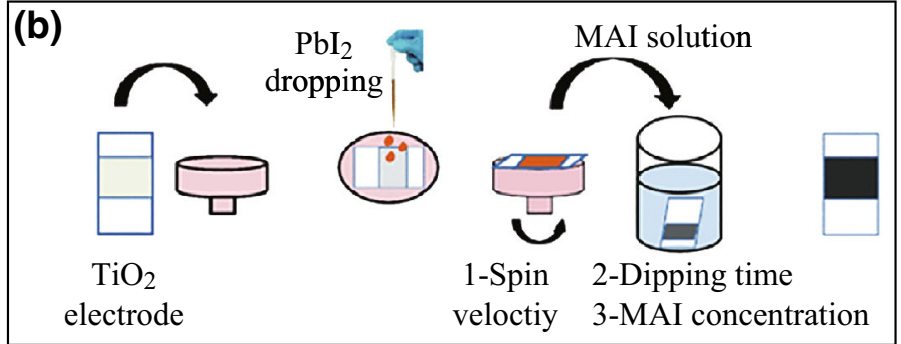

(d)
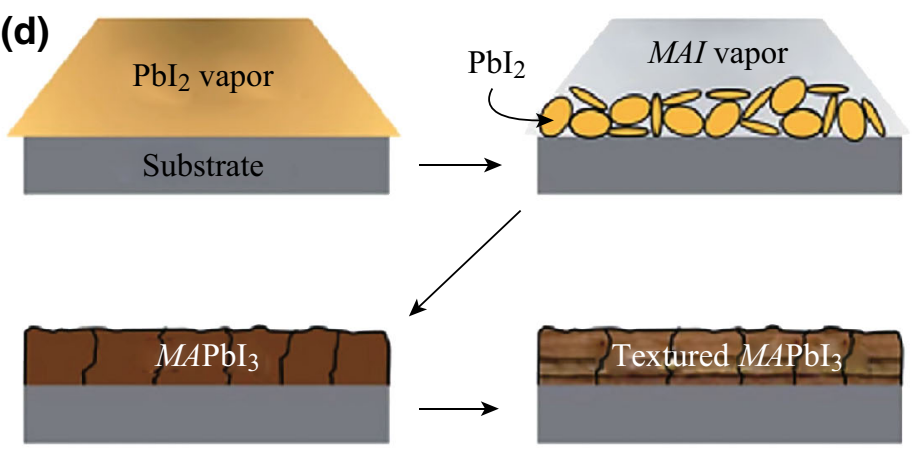

Textured $\mathrm{MAPBI}_{3}$ (e) Substrate
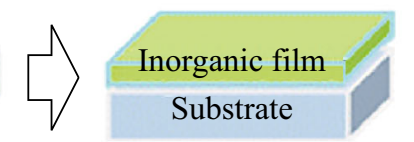

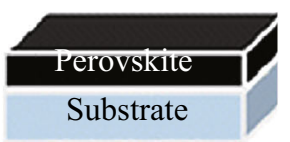

Fig. 15 a One-step deposition. b Two-step sequential deposition. c Dual-source coevaporation. d Sequential vapor deposition. e Vapor-assisted solution growth process. Adapted image reproduced with permission of Ref. [18, 105-107]

$\mathrm{FTO} / \mathrm{cp}-\mathrm{TiO}_{2} / \mathrm{mp}^{-\mathrm{TiO}_{2}} / \mathrm{MAPbI}_{3} /$ spiro-OMeTAD/Au [102] and the other developed by $\mathrm{H}$. Snaith and coworkers deposited a high-quality $\mathrm{MAPbI}_{3-x} \mathrm{Cl}_{x}$ film via dual-source vacuum deposition in a planar heterojunction (PHJ) perovskite solar cell, as shown in Fig. 14. This FTO/cp-TiO ${ }_{2} /$ $\mathrm{MAPbI}_{3-x} \mathrm{Cl}_{x} /$ spiro-OMeTAD/Ag-based device achieved a PCE 15.4\% [4]. Up to now, to the best of our knowledge, Seok and coworkers maintain the record certified PCE of $22.1 \%$ (Fig. 14). Simultaneously, all-inorganic perovskite solar cells have been reported. Liu and coworkers for the first time discovered how to make $\mathrm{CsPbBr}_{3}$ perovskite solar cells out of QDs and achieved 6.7\% conversion efficiency. Recently, Joseph M. Luther and coworkers implemented a low-temperature synthesis of $\alpha-\mathrm{CsPbI}_{3}$ perovskite. The highest PCE of all-inorganic perovskite solar cells reached $10.77 \%$ [103].

As the PCEs of perovskite solar cells are very sensitive to the morphology, composition, uniformity, and solution process, among others, the fabrication of perovskite absorbers must be accurately controlled. The main methods (Fig. 15) include one-step deposition [104] and two-step sequential deposition [4] methods based on solution processing, vacuum deposition [16, 105], and vapor-assisted solution processes [18]. In addition, a fast deposition crystallization (FDC) procedure was developed to yield highly uniform perovskite film consisting of microsized crystals, as illustrated in Fig. 15.

\subsection{Photodetectors}

PDs have a wide range of commercial and scientific applications in imaging, optical fiber communications, spectroscopy, and biomedical applications [108-110]. The commercially available PDs are commonly made by $\mathrm{SiC}$, $\mathrm{Si}$, and $\mathrm{HgCdTe}$ for $\mathrm{UV}$, visible, and infrared detection, respectively [110-114]. Endre Horvá et al. first constructed two-probe detectors based on a few perovskite NWs for 633-nm light detection [49]. Under laser illumination, the 
light-generated electron-hole pairs caused an increase in the conductance of the material up to a factor of 300 (Fig. 16a, b). The calculated responsivity was estimated to be $5 \mathrm{~mA} \mathrm{~W}^{-1}$, comparable (10 times higher) to the value that has been achieved with the first prototypes of those $2 \mathrm{D}$ materials [115, 116]. The response time showed that rise and decay times for the on-off current are less than $500 \mu \mathrm{s}$, $\sim 10^{4}$ faster than the state-of-the-art PDs made of 2D TMD materials [117, 118]. Considering the nonuniformity of random NW PDs, our group utilized aligned NWs arrays to construct conductive PDs and systematically investigated the PD performances [52]. Monolayer NW-based PDs exhibited a response time of $\sim 0.3 \mathrm{~ms}$, a responsivity of $1.3 \mathrm{~A} \mathrm{~W}^{-1}$, and a detectivity of $2.5 \times 10^{12}$ Jones, which are superior to recently reported PD performances based on perovskite thin films and inorganic NWs (Fig. 16c, d).

The above studies were all based on individual PDs. However, the practical applications of PDs (for example, in imaging) require large number of pixels to construct target images. Therefore, our group first utilized perovskite PD arrays and utilized them to preliminarily implement imaging systems [58] (Fig. 16i-o). We developed a modified one-step method to implement the new NW morphology of NW webs. The PD arrays were applied in imaging and successfully obtained clear mapping of the light source signal. The network PD arrays showed superior flexibility, which could withstand wide angle $\left(20^{\circ}-\right.$ $\left.80^{\circ}\right)$ bending over a large number $(\sim 10,000)$ of cycles. Moreover, the sandwich structure (PET/OTP/PMMA) could greatly improve the device stability and the network PD arrays easily stayed intact for one month of storage in air. Our PD responsivity was further optimized by Jie's group [60] (Fig. 16e-h). Large-scale PD arrays were fabricated by doctor blading, and the corresponding responsivity was improved to $13.5 \mathrm{~A} \mathrm{~W}^{-1}$. The representative results of perovskite PDs are summarized in Table 2.

\subsection{Lasing}

Semiconductor NW lasers, owing to their ultracompact physical sizes, highly localized coherent output, and efficient waveguiding, are promising building blocks for nanoscale photonic and optoelectronic devices [120]. Each NW can serve as a waveguide along the axial direction and the two end facets form Fabry-Perot cavities for optical amplification. One of the main obstacles limiting the potential applications of semiconductor NW lasers is the high-threshold carrier density required for lasing. The amazing solar cell performance is ascribed to the long carrier lifetimes and diffusion lengths ( $\mu \mathrm{m}$ range) [121-124]. These properties combined with high fluorescence yield and wavelength tunability [96, 124, 125] render lead halide perovskites as ideal materials for lasing. Song
Jin et al. teamed up with $\mathrm{X}-\mathrm{Y}$. Zhu to develop a surfaceinitiated solution growth strategy to synthesize high-quality single-crystal NWs. NWs below the lasing threshold $\left(P_{\mathrm{Th}}\right)$ showed uniform intensity from the whole NWs, and those above $P_{\mathrm{Th}}$ demonstrated strong emission with spatial interference at the two end facets [126]. They exhibited a quality factor 3600 , which was more than an order higher than that of the state-of-the-art GaAs-AlGaAs core-shell NW laser operating at a temperature of $4 \mathrm{~K}$ [127]. In addition to single-mode lasing, they also observed multiple lasing modes from perovskite NWs. For comparison, the QYs from OIP polycrystalline thin films were $<10 \%$ for spontaneous emission (SPE) and $\sim 15 \%$ for amplified SPE [125]. For another comparison, the state-of-the-art GaAsAlGaAs core-shell NWs laser has a carrier lifetime of $\sim 440$ ps and a QY of $\sim 0.4 \%$ [127]. These comparisons suggest that the unique lasing performance may be ascribed to the exceptionally low trap density in their single-crystal NWs. A major advantage of lead halide perovskites for lasing application was the broad wavelength tunability based on composition stoichiometry [125]. They further demonstrated the color tunability from near-infrared to blue in single-crystal perovskite NWs. By simply mixing different amounts of methylammonium iodide and bromide or bromide and chloride in the precursor solution, they successfully synthesized single-crystal NWs of $\mathrm{MAPbBr}_{y}$ $\mathrm{I}_{3-y}$ and $\mathrm{MAPbCl}_{x} \mathrm{Br}_{3-x}$ alloys with various stoichiometries (Fig. 17a-f). Room-temperature-tunable NW lasers were also implemented by Xiong's group, who adopted organic-inorganic perovskite NWs as the Fabry-Perot cavities to emit lasers [30].

Considering the photo- and thermal stabilities of $\mathrm{MAPbX}_{3} \mathrm{NW}$ lasers, Song Jin et al. reported a low-temperature solution growth of single-crystal NWs of formamidinium lead halide perovskites $\left(\mathrm{FAPbX}_{3}\right)$ that feature redshifted emission and better thermal stability compared to $\mathrm{MAPbX}_{3}$ [129]. They demonstrated optically pumped room-temperature near-infrared $(\sim 820 \mathrm{~nm})$ and green lasing $(\sim 560 \mathrm{~nm})$ from $\mathrm{FAPbI}_{3}$ and $\mathrm{FAPbBr}_{3} \mathrm{NWs}$ with low lasing thresholds of several microjoules per square centimeter and high quality factors of approximately 1500-2300. More remarkably, the $\mathrm{FAPbI}_{3}$ and MABr-stabilized $\mathrm{FAPbI}_{3}$ NWs displayed durable room-temperature lasing under $\sim 10^{8}$ shots of sustained illumination, greatly exceeding the stability of $\mathrm{MAPbI}_{3}\left(\sim 10^{7}\right.$ laser shots). They also demonstrated tunable NWs lasers in a wider wavelength region from FA-based lead halide perovskite alloys through cation and anion exchange (Fig. 17h-i).

Since organic-inorganic lead halide perovskite materials were still limited by their instability. Full-inorganic halide perovskites, cesium lead halides, offered a robust candidate without sacrificing emission tunability or ease of synthesis. Thus, Yang et al. reported the low-temperature, solution- 
(a)

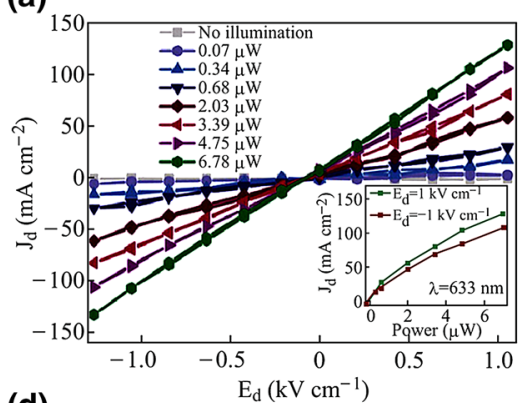

(d)

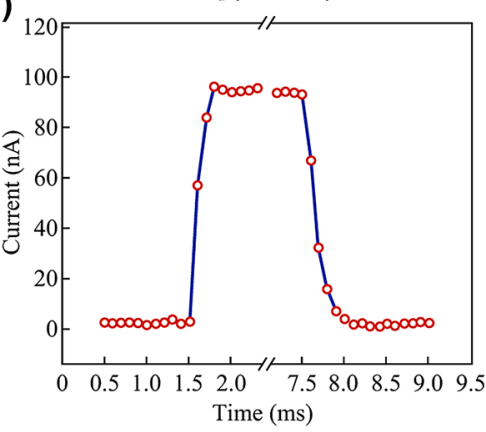

(g)

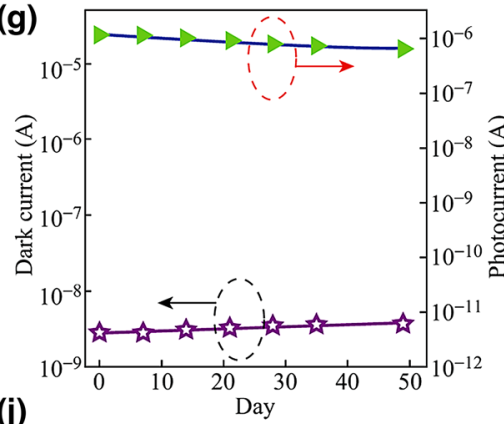

(j)
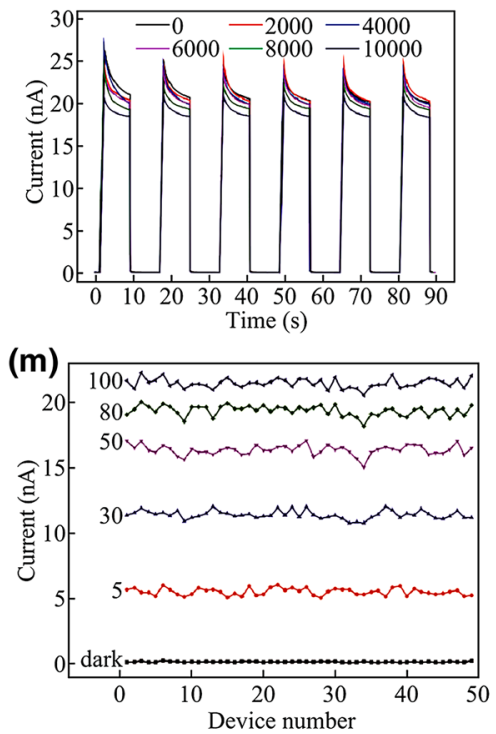

(b)

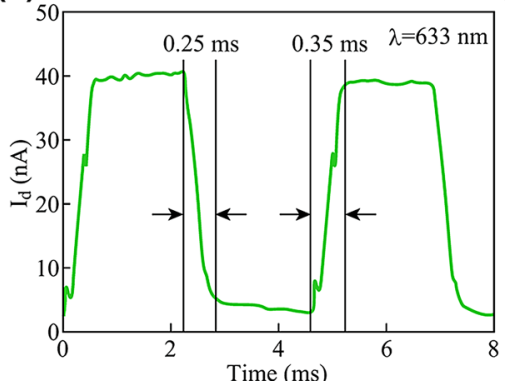

(e)

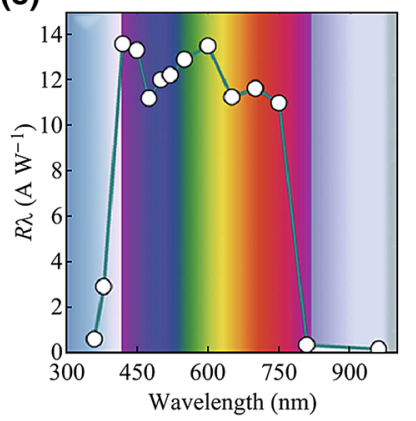

(h)

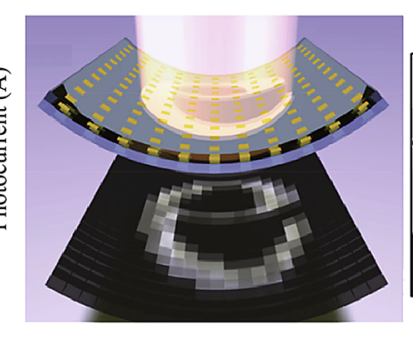

(k)

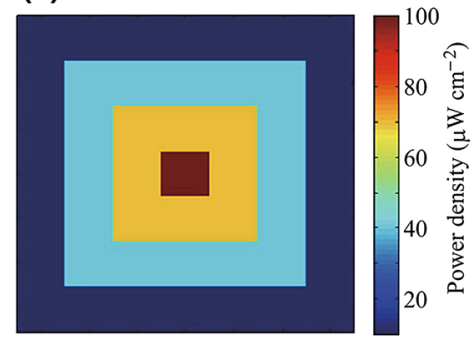

(n)
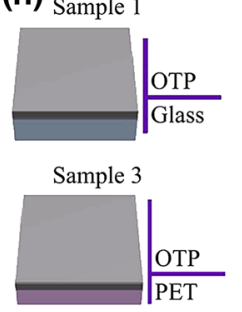

(c)

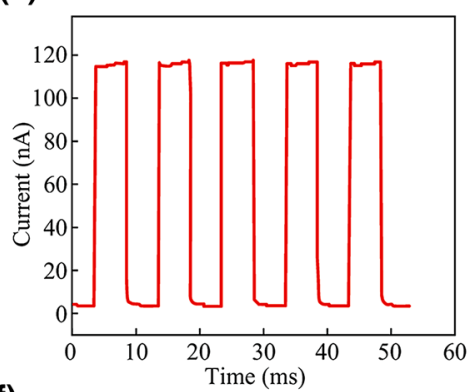

(f)

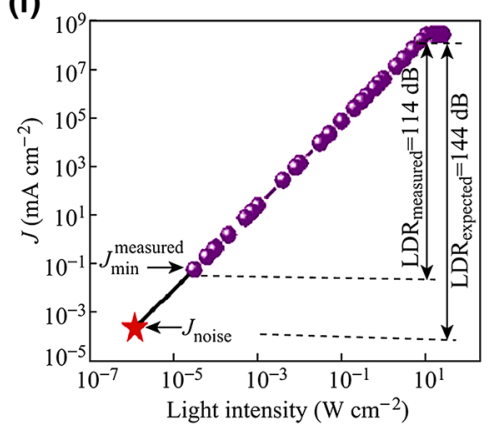

(i)

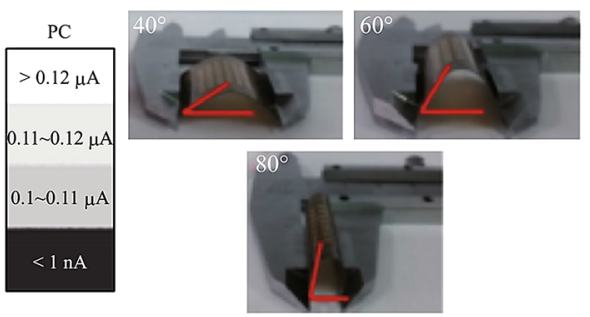

(I)

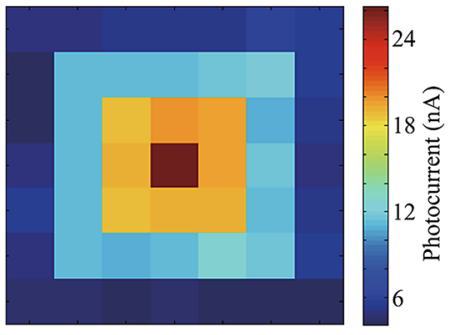

(o)

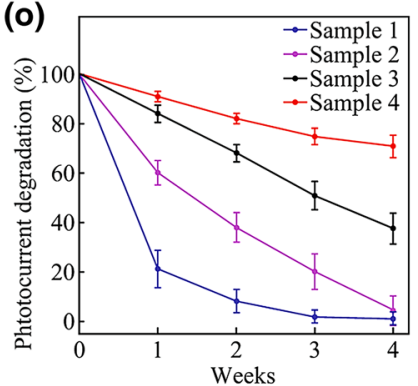

Fig. 16 Perovskite NW photodetectors: slip coating-based NWs PDs. a Dark and laser-illuminated $I-V$ curves. b Time-resolved photoresponse. EISA method-based device performances. c $I-t$ curves. d High-resolution scan to one cycle of $I-t$ curves. Doctor blading-based NW PDs. e Wavelength-dependent photoresponsivity of the $\mathrm{CH}_{3} \mathrm{NH}_{3} \mathrm{PbI}_{3} \mathrm{MW}$ array-based photodetectors. $\mathbf{f}$ Photocurrent versus light intensity curves. g Variation of dark current/photocurrent with day of photodetector based on OTP MW arrays. h Perovskite MW PD arrays for light source mapping. NW web-based PDs for imaging. i-j j Flexibility performances. $\mathbf{k}-\mathbf{m}$ NW network PD arrays for imaging. $\mathbf{n}, \mathbf{o}$ Encapsulation could help to improve the device stability. Adapted image reproduced with permission of Ref. $[49,52,60]$ 
Table 2 Overview of selected representative results of perovskite PDs [49, 52, 54-57, 119]

\begin{tabular}{|c|c|c|c|c|c|}
\hline Materials & Configuration & Responsivity $\left(\mathrm{A} \mathrm{W}^{-1}\right)$ & Detectivity (Jones) & Response time & Report year \\
\hline $\mathrm{CH}_{3} \mathrm{NH}_{3} \mathrm{PbI}_{3} / \mathrm{TiO}_{2}$ film & Photodetector & $0.49 \times 10^{-6}$ & - & $0.02 \mathrm{~s}$ & 2014 \\
\hline $\mathrm{CH}_{3} \mathrm{NH}_{3} \mathrm{PbI}_{3}$ film & Photodetector & 3.49 & - & $<0.2 \mathrm{~s}$ & 2014 \\
\hline $\mathrm{CH}_{3} \mathrm{NH}_{3} \mathrm{PbI}_{3-x} \mathrm{CI}_{x}$ film & Photodetector & $5 \times 10^{-3}$ & $10^{14}$ & $160 \mathrm{~ns}$ & 2014 \\
\hline $\mathrm{CH}_{3} \mathrm{NH}_{3} \mathrm{PbI}_{3}$ nanowires & Phototransistor & 14.5 & - & $<500 \mu \mathrm{s}$ & 2015 \\
\hline $\mathrm{CH}_{3} \mathrm{NH}_{3} \mathrm{PbI}_{3}$ film & Photodetector & 180 & - & $0.2 \mu \mathrm{s}$ & 2015 \\
\hline Graphene- $\mathrm{CH}_{3} \mathrm{NH}_{3} \mathrm{PbI}_{3}$ composites & Phototransistor & 242 & $10^{9}$ & $87 \mathrm{~ms}$ & 2015 \\
\hline $\mathrm{CH}_{3} \mathrm{NH}_{3} \mathrm{PbI}_{3}$ film & Photodetector & - & - & $5.7 \pm 1.0 \mu \mathrm{s}$ & 2015 \\
\hline $\mathrm{CH}_{3} \mathrm{NH}_{3} \mathrm{PbI}_{3}$ film & Photodiode & - & $3 \times 10^{12}$ & $<5 \mu \mathrm{s}$ & 2015 \\
\hline $\mathrm{CH}_{3} \mathrm{NH}_{3} \mathrm{PbI}_{3}$ film & Photodetector & - & $7.4 \times 10^{12}$ & $120 \mathrm{~ns}$ & 2015 \\
\hline $\mathrm{CH}_{3} \mathrm{NH}_{3} \mathrm{PbI}_{3}$ film & Optocoupler & 1.0 & - & $20 \mu \mathrm{s}$ & 2015 \\
\hline $\mathrm{CH}_{3} \mathrm{NH}_{3} \mathrm{PbI}_{3}$ nanowires & Photodetector & 1.3 & $2.5 \times 10^{12}$ & $0.3 \mathrm{~ms}$ & 2015 \\
\hline
\end{tabular}
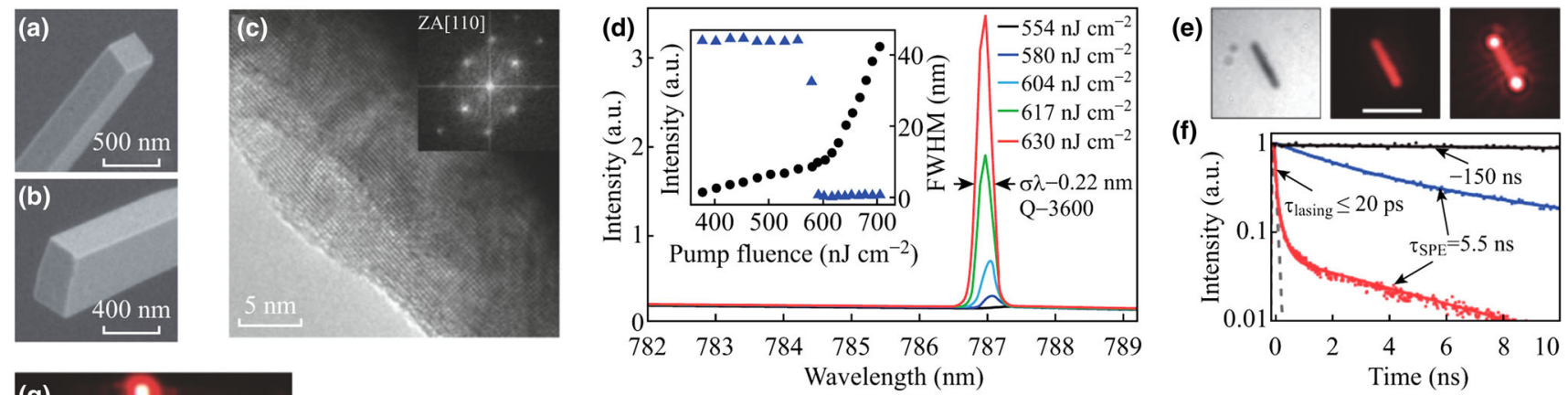
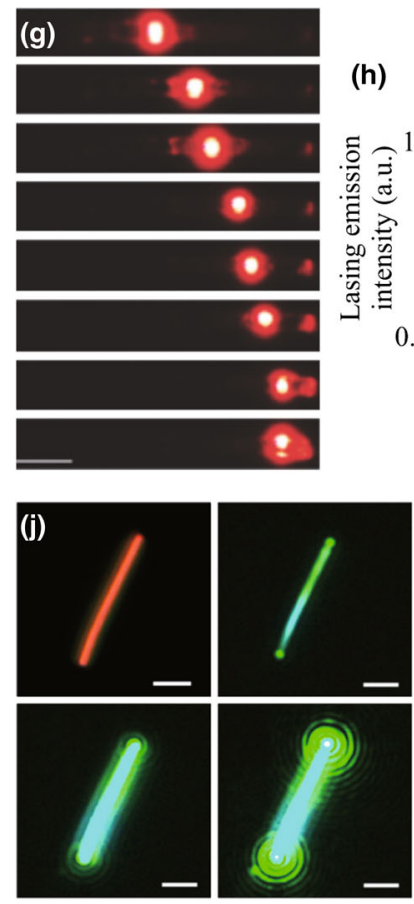
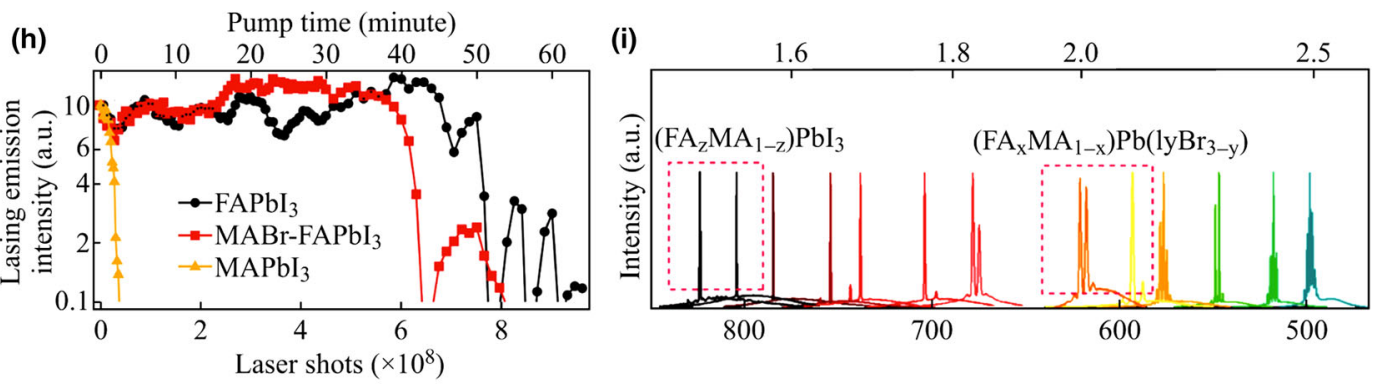
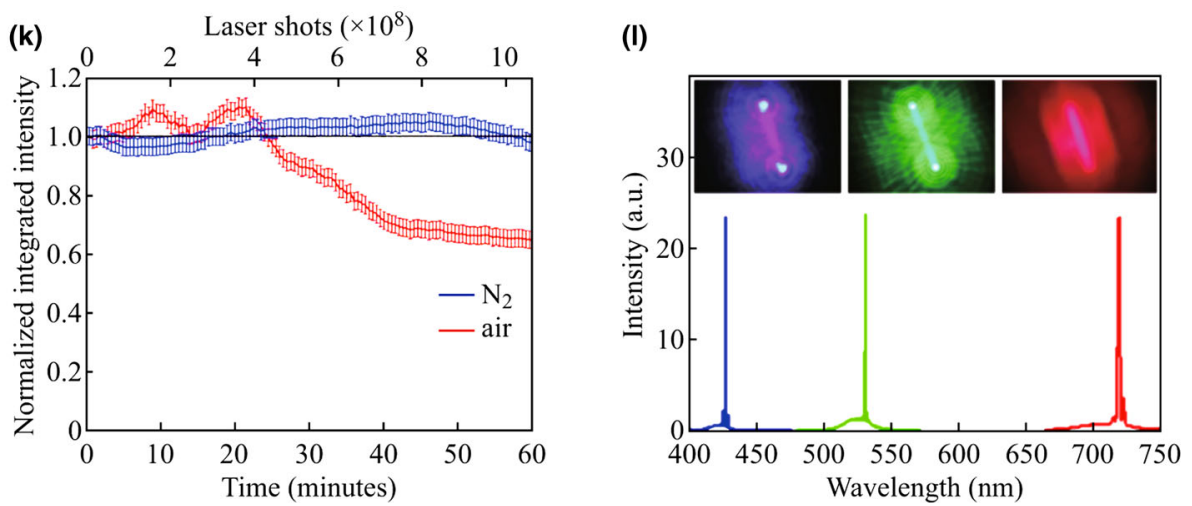

Fig. 17 Perovskite NWs lasers. a-f SEM image and nanolaser performances from MAPbX 3 NWs. $\mathbf{g}$ A set of dark-field images of a IOP MW waveguide. Scale bar is $10 \mu \mathrm{m} . \mathbf{h}, \mathbf{i}$ FAPbX 3 NW laser performances. j-l Full-inorganic halide perovskite NW lasers. Adapted image reproduced with permission of Ref. [67, 119, 128, 129] 
phase growth of cesium lead halide NWs showing lowthreshold lasing and high stability [119]. Upon optical excitation, Fabry-Perot lasing occurred in $\mathrm{CsPbBr}_{3} \mathrm{NWs}$ with an onset of $5 \mu \mathrm{J} \mathrm{cm}{ }^{-2}$ with the NW cavity displaying a maximum quality factor of $1009 \pm 5$. Lasing under constant, pulsed excitation could be maintained for over $1 \mathrm{~h}$, the equivalent of $10^{9}$ excitation cycles. Wavelength tunability in the green and blue regions and excellent stability promised those NW lasers as attractive for device applications (Fig. 17j-1). The light-matter interactions of NW lasers were investigated by Jae Kyu Song et al. [66]. The reduced mode volume of the NWs suggested strong light-matter interactions with an exciton-polariton model. The representative results of perovskite nanolasers are summarized in Table 3.

\section{Summary and Outlook}

In summary, we have reviewed recent developments of structure and growth of low-dimensional halide perovskites and their applications for high-performance optoelectronic devices. Their remarkable intrinsic properties and high degree of structural flexibility allow the potential beyond academic curiosity and industrial interest. In particular, the high QY, narrow emission, high exciton binding energies, color tunability, and facile solution processing at low temperatures have been outlined. Beyond applications as active layers for emitters and optical gain materials, low- dimensional halide perovskites may also be incorporated in currently existing technologies as a candidate to replace phosphors. As the field grows from its infancy stage, various kinds of heterojunctions, architectures, and processing conditions are probable to promote rapid development. For the routes toward commercialization, the key issues such as the optoelectronic properties (e.g., excitation dynamics, nonradiative recombination), working principles, and degradation mechanisms need better understanding. Owing to the successes in photovoltaics, it is reasonable to expect that the research in other perovskite optoelectronics will intensify and usher in a bright future for PDs, lasers, and light-emitting devices (Table 4).

For low-dimensional halide perovskite synthesis, the perovskite formation processes play a paramount role in determining their final device performances. They can be prepared by a variety of techniques via the competition between in situ transformation and dissolution-crystallization mechanisms. Moreover, the use of capping ligands and solvent engineering can help to tailor the shape of perovskite crystals. Emerging applications of these randomly distributed perovskite units require the achievement of controllable alignment in order to match the planar microelectronic fabrication techniques.

Beyond PV applications, low-dimensional perovskite materials with high crystallinity, emission efficiency, and benign defects enable the fabrication of LEDs, lasers, PDs, and other optoelectronic/microelectronic devices. Furthermore, their high atomic number and high density may find

Table 3 Representative results of the ASE/lasing from perovskite gain media [76, 119, 123-126, 130-132]

\begin{tabular}{|c|c|c|c|c|c|c|c|}
\hline $\begin{array}{l}\text { Materials } \\
\left(X=\mathrm{CI}^{-}, \mathrm{Br}^{-},\right. \\
\left.\text {or } \mathrm{I}^{-}\right)\end{array}$ & Morphology & Pump source & $\begin{array}{l}\text { S.E } \\
\text { wavelengths } \\
(\mathrm{nm})\end{array}$ & $\begin{array}{l}\text { Modal } \\
\text { gain } \\
\text { coefficient }\end{array}$ & $\begin{array}{l}\text { Threshold } \\
\text { (ASE or } \\
\text { lasing) }\end{array}$ & Cavity type & $\begin{array}{l}\text { Publication } \\
\text { date }\end{array}$ \\
\hline $\mathrm{CH}_{3} \mathrm{NH}_{3} \mathrm{PbX}_{3}$ & Thin film & $600 \mathrm{~nm}, 150 \mathrm{fs}$ & $500-790$ & 40 & 12 (ASE) & N.A & 03-2014 \\
\hline $\mathrm{CH}_{3} \mathrm{NH}_{3} \mathrm{PbI}_{3}$ & Thin film & $530 \mathrm{~nm}, 4 \mathrm{~ns}$ & 780 & - & 10 (ASE) & N.A & 08-2015 \\
\hline $\mathrm{CH}_{3} \mathrm{NH}_{3} \mathrm{PbI}_{3-x} \mathrm{Cl}_{x}$ & Thin film & $532 \mathrm{~nm}, 400 \mathrm{ps}$ & 760 & - & $\begin{array}{l}120(\mathrm{ASE}) \\
0.2 \mu \mathrm{J} \text { per pulse } \\
\quad \text { (lasing) }\end{array}$ & $\begin{array}{l}\text { N.A } \\
\text { Vertical microcavity }\end{array}$ & $04-2014$ \\
\hline $\mathrm{CH}_{3} \mathrm{NH}_{3} \mathrm{PbI}_{3}$ & Thin film & $355 \mathrm{~nm}, 2 \mathrm{~ns}$ & 775 & 125 & $\begin{array}{l}65 \text { (ASE) } \\
75 \text { (lasing) }\end{array}$ & $\begin{array}{l}\text { N.A } \\
\text { Spherical WGM }\end{array}$ & $10-2014$ \\
\hline $\mathrm{CH}_{3} \mathrm{NH}_{3} \mathrm{PbI}_{3}$ & Thin film & $532,1 \mathrm{~ns}$ & 780 & - & 0.32 (lasing) & DFB & $12-2015$ \\
\hline $\mathrm{CH}_{3} \mathrm{NH}_{3} \mathrm{PbBr}_{3}$ & Square microdisk & $400 \mathrm{~nm}, 120 \mathrm{fs}$ & 550 & - & 4 (lasing) & Planar WGM & $04-2015$ \\
\hline $\mathrm{CH}_{3} \mathrm{NH}_{3} \mathrm{PbI}_{3-x} \mathrm{Cl}_{x}$ & Microplatelet & $400 \mathrm{~nm}, 50 \mathrm{fs}$ & 760 & - & 40 (lasing) & Planar WGM & 08-2014 \\
\hline $\mathrm{CH}_{3} \mathrm{NH}_{3} \mathrm{PbI}_{3}$ & Microcrystal networks & $355 \mathrm{~nm}, 0.8 \mathrm{~ns}$ & 765 & - & 200 (lasing) & Random lasing & $10-2014$ \\
\hline $\mathrm{CH}_{3} \mathrm{NH}_{3} \mathrm{PbX}_{3}$ & NWs & $402 \mathrm{~nm}, 150 \mathrm{fs}$ & $500-780$ & - & 0.2 (lasing) & Fabry-Perot cavity & 03-2015 \\
\hline $\mathrm{CsPbX}_{3}$ & NPs & $400 \mathrm{~nm}, 100 \mathrm{fs}$ & $470-620$ & 98 & $\begin{array}{l}22 \text { (ASE) } 11 \times 10^{3} \\
\quad \text { (lasing) }\end{array}$ & N.A ring WGM & $10-2015$ \\
\hline $\mathrm{CsPbX}_{3}$ & NPs & $400 \mathrm{~nm}, 100 \mathrm{fs}$ & $470-640$ & 450 & $\begin{array}{l}\text { 5-22 (ASE) } \\
\text { N.A (lasing) }\end{array}$ & $\begin{array}{l}\text { N.A } \\
\text { Spherical WGM } \\
\text { Random lasing }\end{array}$ & $07-2015$ \\
\hline $\mathrm{CsPbBr}_{3}$ & NPs & $800 \mathrm{~nm}, 35 \mathrm{fs}$ & 520 & - & $12 \times 10^{3}(\mathrm{ASE})$ & N.A & $12-2015$ \\
\hline $\mathrm{CsPbr}_{3}$ & NWs & $400 \mathrm{~nm}, 150 \mathrm{fs}$ & 530 & - & 10 (lasing) & Fabry-Perot cavity & $02-2016$ \\
\hline
\end{tabular}


Table 4 Stability improvement strategies for perovskite [103, 130-136]

\begin{tabular}{llll}
\hline Perovskite & Passivation materials & Method & Report time \\
\hline $\mathrm{CsPbX}$ & The incorporation of poly(maleic anhydride-alt-L-octadecene) (PMA) & Tightening the ligand binding & 2016 \\
$\mathrm{CsPB}_{3}$ & A polyhedral oligomeric silsesquioxane (POSS) & Surface protection & 2016 \\
$\mathrm{CsPX}_{3}$ & (3-aminopropyl)triethoxysilane (APTES) & A silica matrix & X-ray illumination \\
$\mathrm{CsPX}_{3}$ & - & Intermolecular C $=\mathrm{C}$ bonding & 2016 \\
$\mathrm{CsPX}_{3}$ & - & Coupling with perovskites & 2016 \\
$\mathrm{CH}_{3} \mathrm{NH}_{3} \mathrm{PbBr}_{3}$ & $\mathrm{SiO}_{2}$ & Capping nanocrystals & 2016 \\
$\mathrm{FAPbBr}$ & Hydrophobic association & Chloride doping & 2016 \\
$\mathrm{CsPbX}$ & Chloride & &
\end{tabular}

applicability to high-energy radiation detection. Additionally, perovskites exhibit interesting ferroelectric properties, potentially due to the free rotation of the polar organic species, which further bolsters their potential for switchable electronics and memory devices. Despite the novel properties of low-dimensional perovskites, several crucial challenges, including toxicity and instability, limit wide industrial application. Limited success has been reported for the replacement of $\mathrm{Pb}$ with environmental friendly elements. Nontoxic Sn shares relatively similar properties to $\mathrm{Pb}$ in hybrid perovskites and is theoretically expected to yield more efficient performances. However, Sn-based perovskite solar cells experience more serious instability due to the naturally favorable oxidation of $\mathrm{Sn}$ (II), which inevitably requires advanced encapsulation techniques. Apart from the toxicity, $\mathrm{Pb}$-based perovskites experience inherent instability under long-term operation, which is even more urgent to address. The degradation mechanisms of perovskites upon exposure to thermal, moisture, UV, and mechanical conditions require a reliable strategy in order to improve material stability. Encouraging results have been demonstrated through interface modifications between transport materials and electrodes [121]. Optimized devices have realized stable working times over 1000 h. However, considering the durability requirements of 20 years operation for solar cells, there is still much work required to improve the intrinsic properties of halide perovskites and more stable device structures. From an academic research perspective, there have been great success for the synthesis and applications of halide perovskites. Further research efforts are expected to focus on: (1) deep understanding of the structure-property relationships of the entire hybrid material system to guide the rational design and careful manipulation of the optoelectronic properties and (2) introducing new ideas to break the trade-off between the halide perovskite novelties and the working stability. Under the intensely driven research, the future development of environmentally friendly and reliably working perovskite devices is hopeful.
Acknowledgements This work is supported by the Doctoral Program of Higher Education (20130142120075), the Fundamental Research Funds for the Central Universities (HUST:2016YXMS032) and National Key Research and Development Program of China (Grant No. 2016YFB0700702). The authors also thank Testing Center of HUST and the Center for Nanoscale Characterization and Devices, Wuhan National Laboratory for Optoelectronics (WNLO) for facility access.

Open Access This article is distributed under the terms of the Creative Commons Attribution 4.0 International License (http://crea tivecommons.org/licenses/by/4.0/), which permits unrestricted use, distribution, and reproduction in any medium, provided you give appropriate credit to the original author(s) and the source, provide a link to the Creative Commons license, and indicate if changes were made.

\section{References}

1. A. Rogach, Quantum dots still shining strong 30 years on. ACS Nano 8(7), 6511-6512 (2014). doi:10.1021/nn5036922

2. A.L. Rogach, Semiconductor nanocrystal quantum dots. WienNew York: Springer(2008).

3. S. González-Carrero, R.E. Galian, J. Pérez-Prieto, Organometal halide perovskites: bulk low-dimension materials and nanoparticles. Part. Part. Syst. Charact. 32(7), 709-720 (2015). doi:10. 1002/ppsc. 201400214

4. J. Burschka, N. Pellet, S.-J. Moon, R. Humphry-Baker, P. Gao, M.K. Nazeeruddin, M. Grätzel, Sequential deposition as a route to high-performance perovskite-sensitized solar cells. Nature 499(7458), 316-319 (2013). doi:10.1038/nature12340

5. H.-S. Kim, C.-R. Lee, J.-H. Im, K.-B. Lee, T. Moehl et al., Lead iodide perovskite sensitized all-solid-state submicron thin film mesoscopic solar cell with efficiency exceeding $9 \%$. Sci. Rep. 2(8), 591 (2012). doi:10.1038/srep00591

6. www.nrel.gov/ncpv/images/efficiency_chart.jpg

7. C. Zhang, Y. Luo, X. Chen, Y. Chen, Z. Sun, S. Huang, Effective improvement of the photovoltaic performance of carbon-based perovskite solar cells by additional solvents. NanoMicro Lett. 8(4), 347-357 (2016). doi:10.1007/s40820-0160094-4

8. M. Pena, J. Fierro, Chemical structures and performance of perovskite oxides. Chem. Rev. 101(7), 1981-2018 (2001). doi:10.1021/cr980129f

9. M. García-Hernández, G. Chadeyron, D. Boyer, A. GarcíaMurillo, F. Carrillo-Romo, R. Mahiou, Hydrothermal synthesis 
and characterization of Europium-doped barium titanate nanocrystallites. Nano-Micro Lett. 5(1), 57-65 (2013). doi:10. 1007/BF03353732

10. Q. Chen, N. De Marco, Y.M. Yang, T.-B. Song, C.-C. Chen, H. Zhao, Z. Hong, H. Zhou, Y. Yang, Under the spotlight: the organic-inorganic hybrid halide perovskite for optoelectronic applications. Nano Today 10(3), 355-396 (2015). doi:10.1016/j. nantod.2015.04.009

11. D.B. Mitzi, Synthesis, structure, and properties of organicinorganic perovskites and related materials. Prog. Inorg. Chem. 48, 1-121 (2007). doi:10.1002/9780470166499.ch1

12. M.A. Green, A. Ho-Baillie, H.J. Snaith, The emergence of perovskite solar cells. Nat. Photonics 8(7), 506-514 (2014). doi: $10.1038 /$ nphoton. 2014.134

13. A. Kojima, K. Teshima, Y. Shirai, T. Miyasaka, Organometal halide perovskites as visible-light sensitizers for photovoltaic cells. J. Am. Chem. Soc. 131(17), 6050-6051 (2009). doi:10. 1021/ja809598r

14. J.-H. Im, C.-R. Lee, J.-W. Lee, S.-W. Park, N.-G. Park, 6.5\% efficient perovskite quantum-dot-sensitized solar cell. Nanoscale 3(10), 4088-4093 (2011). doi:10.1039/C1NR10867K

15. M.M. Lee, J. Teuscher, T. Miyasaka, T.N. Murakami, H.J. Snaith, Efficient hybrid solar cells based on meso-superstructured organometal halide perovskites. Science 338(6107), 643-647 (2012). doi:10.1126/science.1228604

16. M. Liu, M.B. Johnston, H.J. Snaith, Efficient planar heterojunction perovskite solar cells by vapour deposition. Nature 501(7467), 395-398 (2013). doi:10.1038/nature12509

17. J.Y. Jeng, Y.F. Chiang, M.H. Lee, S.R. Peng, T.F. Guo, P. Chen, T.C. Wen, $\mathrm{CH}_{3} \mathrm{NH}_{3} \mathrm{PbI}_{3}$ perovskite/fullerene planar-heterojunction hybrid solar cells. Adv. Mater. 25(27), 3727-3732 (2013). doi:10.1002/adma.201301327

18. Q. Chen, H. Zhou, Z. Hong, S. Luo, H.-S. Duan, H.-H. Wang, Y. Liu, G. Li, Y. Yang, Planar heterojunction perovskite solar cells via vapor-assisted solution process. J. Am. Chem. Soc. 136(2), 622-625 (2013). doi:10.1021/ja411509g

19. V.M. Goldschmidt, Die gesetze der krystallochemie. Naturwissenschaften 14(21), 477-485 (1926). doi:10.1007/BF01507527

20. C. Li, X. Lu, W. Ding, L. Feng, Y. Gao, Z. Guo, Formability of $\mathrm{ABX} 3(\mathrm{X}=\mathrm{F}, \mathrm{Cl}, \mathrm{Br}, \mathrm{I})$ halide perovskites. Acta Crystallogr. Sect. B: Struct. Sci. 64(6), 702-707 (2008). doi:10.1107/ S0108768108032734

21. G. Kieslich, S. Sun, A.K. Cheetham, Solid-state principles applied to organic-inorganic perovskites: new tricks for an old dog. Chem. Sci. 5(12), 4712-4715 (2014). doi:10.1039/ c4sc02211d

22. D.B. Mitzi, Templating and structural engineering in organicinorganic perovskites. J. Chem. Soc., Dalton Trans. (1), 1-12 (2001). doi:10.1039/b007070j

23. M.I. Saidaminov, A.L. Abdelhady, B. Murali, E. Alarousu, V.M. Burlakov et al., High-quality bulk hybrid perovskite single crystals within minutes by inverse temperature crystallization. Nat. Commun. 6, 7586 (2015). doi:10.1038/ncomms 8586

24. Q. Zhang, S.T. Ha, X. Liu, T.C. Sum, Q. Xiong, Room-temperature near-infrared high-Q perovskite whispering-gallery planar nanolasers. Nano Lett. 14(10), 5995-6001 (2014). doi:10. $1021 / \mathrm{nl} 503057 \mathrm{~g}$

25. S. Gonzalez-Carrero, R.E. Galian, J. Pérez-Prieto, Maximizing the emissive properties of $\mathrm{CH} 3 \mathrm{NH} 3 \mathrm{PbBr} 3$ perovskite nanoparticles. J. Mater. Chem. A 3(17), 9187-9193 (2015). doi:10.1039/c4ta05878

26. H. Huang, A.S. Susha, S.V. Kershaw, T.F. Hung, A.L. Rogach, Control of emission color of high quantum yield $\mathrm{CH}_{3} \mathrm{NH}_{3} \mathrm{PbBr}_{3}$ perovskite quantum dots by precipitation temperature. Adv. Sci. 2(9), 581-583 (2015). doi:10.1002/advs.201500194
27. H.Z. Feng Zhang, C. Chen, X. Wu, X. Hu, H. Huang, J. Han, B. Zou, Y. Dong, Brightly luminescent and color-tunable colloidal $\mathrm{CH}_{3} \mathrm{NH}_{3} \mathrm{PbX}_{3}(\mathrm{X}=\mathrm{Br}, \mathrm{I}, \mathrm{Cl})$ quantum dots: potential alternatives for display technology. ACS Nano 9(4), 4533-4542 (2015). doi:10.1021/acsnano.5b01154

28. L.C. Schmidt, A. Pertegás, S. González-Carrero, O. Malinkiewicz, S. Agouram et al., Nontemplate synthesis of $\mathrm{CH}_{3-}$ $\mathrm{NH}_{3} \mathrm{PbBr}_{3}$ perovskite nanoparticles. J. Am. Chem. Soc. 136(3), 850-853 (2014). doi:10.1021/ja4109209

29. P. Tyagi, S.M. Arveson, W.A. Tisdale, Colloidal organohalide perovskite nanoplatelets exhibiting quantum confinement. J. Phys. Chem. Lett. 6(10), 1911-1916 (2015). doi:10.1021/acs. jpclett.5b00664

30. A.B. Wong, M. Lai, S.W. Eaton, Y. Yu, E. Lin, L. Dou, A. Fu, P. Yang, Growth and anion exchange conversion of $\mathrm{CH}_{3} \mathrm{NH}_{3-}$ $\mathrm{PbX}_{3}$ nanorod arrays for light-emitting diodes. Nano Lett. 15(8), 5519-5524 (2015). doi:10.1021/acs.nanolett.5b02082

31. J. Xing, X.F. Liu, Q. Zhang, S.T. Ha, Y.W. Yuan, C. Shen, T.C. Sum, Q. Xiong, Vapor phase synthesis of organometal halide perovskite nanowires for tunable room-temperature nanolasers. Nano Lett. 15(7), 4571-4577 (2015). doi:10.1021/acs.nanolett. 5b01166

32. J.A. Sichert, Y. Tong, N. Mutz, M. Vollmer, S. Fischer et al., Quantum size effect in organometal halide perovskite nanoplatelets. Nano Lett. 15(10), 6521-6527 (2015). doi:10.1021/acs. nanolett.5b02985

33. X. Peng, L. Manna, W. Yang, J. Wickham, E. Scher, A. Kadavanich, A.P. Alivisatos, Shape control of CdSe nanocrystals. Nature 404(6773), 59-61 (2000). doi:10.1038/35003535

34. L. Peng, A. Tang, C. Yang, F. Teng, Size-controlled synthesis of highly luminescent organometal halide perovskite quantum dots. J. Alloys Compd. 687, 506-513 (2016). doi:10.1016/j.jallcom. 2016.06.162

35. S. Pathak, N. Sakai, F. Wisnivesky Rocca Rivarola, S.D. Stranks, J. Liu et al., Perovskite crystals for tunable white light emission. Chem. Mater. 27(23), 8066-8075 (2015). doi:10.1021/ acs.chemmater. 5 b03769

36. A. Sadhanala, S. Ahmad, B. Zhao, N. Giesbrecht, P.M. Pearce et al., Blue-green color tunable solution processable organolead chloride-bromide mixed halide perovskites for optoelectronic applications. Nano Lett. 15(9), 6095-6101 (2015). doi:10.1021/ acs.nanolett.5b02369

37. L. Protesescu, S. Yakunin, M.I. Bodnarchuk, F. Krieg, R. Caputo et al., Nanocrystals of cesium lead halide perovskites $\left(\mathrm{CsPbX}_{3}, \mathrm{X}=\mathrm{Cl}, \mathrm{Br}\right.$, and I): novel optoelectronic materials showing bright emission with wide color gamut. Nano Lett. 15(6), 3692-3696 (2015). doi:10.1021/n15048779

38. Q.A. Akkerman, V. D'Innocenzo, S. Accornero, A. Scarpellini, A. Petrozza, M. Prato, L. Manna, Tuning the optical properties of cesium lead halide perovskite nanocrystals by anion exchange reactions. J. Am. Chem. Soc. 137(32), 10276-10281 (2015). doi:10.1021/jacs.5b05602

39. G. Nedelcu, L. Protesescu, S. Yakunin, M.I. Bodnarchuk, M.J. Grotevent, M.V. Kovalenko, Fast anion-exchange in highly luminescent nanocrystals of cesium lead halide perovskites $\left(\mathrm{CsPbX}_{3}, \mathrm{X}=\mathrm{Cl}, \mathrm{Br}, \mathrm{I}\right)$. Nano Lett. 15(8), 5635-5640 (2015). doi:10.1021/acs.nanolett.5b02404

40. A. Swarnkar, R. Chulliyil, V.K. Ravi, M. Irfanullah, A. Chowdhury, A. Nag, Colloidal $\mathrm{CsPbBr}_{3}$ perovskite nanocrystals: luminescence beyond traditional quantum dots. Angew. Chem. 127(51), 15644-15648 (2015). doi:10.1002/anie. 201508276

41. Y. Yin, A.P. Alivisatos, Colloidal nanocrystal synthesis and the organic-inorganic interface. Nature 437(7059), 664-670 (2005). doi:10.1038/nature04165 
42. B. Luo, Y.-C. Pu, Y. Yang, S.A. Lindley, G. Abdelmageed, H. Ashry, Y. Li, X. Li, J.Z. Zhang, Synthesis, optical properties, and exciton dynamics of organolead bromide perovskite nanocrystals. J. Phys. Chem. C 119(47), 26672-26682 (2015). doi:10.1021/acs.jpcc.5b08537

43. N. Pradhan, D. Reifsnyder, R. Xie, J. Aldana, X. Peng, Surface ligand dynamics in growth of nanocrystals. J. Am. Chem. Soc. 129(30), 9500-9509 (2007). doi:10.1021/ja0725089

44. M.C. Weidman, M. Seitz, S.D. Stranks, W.A. Tisdale, Highly tunable colloidal perovskite nanoplatelets through variable cation, metal, and halide composition. ACS Nano 10(8), 7830-7839 (2016). doi:10.1021/acsnano.6b03496

45. D.N. Dirin, S. Dreyfuss, M.I. Bodnarchuk, G. Nedelcu, P. Papagiorgis, G. Itskos, M.V. Kovalenko, Lead halide perovskites and other metal halide complexes as inorganic capping ligands for colloidal nanocrystals. J. Am. Chem. Soc. 136(18), 6550-6553 (2014). doi:10.1021/ja5006288

46. Z. Ning, X. Gong, R. Comin, G. Walters, F. Fan et al., Quantumdot-in-perovskite solids. Nature 523(7560), 324-328 (2015). doi:10.1038/nature14563

47. R.S. Sanchez, M.S. de la Fuente, I. Suarez, G. Muñoz-Matutano, J.P. Martinez-Pastor, I. Mora-Sero, Tunable light emission by exciplex state formation between hybrid halide perovskite and core/shell quantum dots: implications in advanced LEDs and photovoltaics. Sci. Adv. 2(1), e1501104 (2016). doi:10.1126/ sciadv. 1501104

48. K. Wu, G. Liang, Q. Shang, Y. Ren, D. Kong, T. Lian, Ultrafast interfacial electron and hole transfeR from $\mathrm{CsPbBr}_{3}$ perovskite quantum dots. J. Am. Chem. Soc. 137(40), 12792-12795 (2015). doi: $10.1021 /$ jacs. 5 b08520

49. E. Horvath, M. Spina, Z. Szekrenyes, K. Kamaras, R. Gaal, D. Gachet, L. Forro, Nanowires of methylammonium lead iodide $\left(\mathrm{CH}_{3} \mathrm{NH}_{3} \mathrm{PbI}_{3}\right)$ prepared by low temperature solution-mediated crystallization. Nano Lett. 14(12), 6761-6766 (2014). doi:10. 1021/n15020684

50. E. Mosconi, A. Amat, M.K. Nazeeruddin, M. Grätzel, F. De Angelis, First-principles modeling of mixed halide organometal perovskites for photovoltaic applications. J. Phys. Chem. C 117(27), 13902-13913 (2013). doi:10.1021/jp4048659

51. M. Xiao, F. Huang, W. Huang, Y. Dkhissi, Y. Zhu et al., A fast deposition-crystallization procedure for highly efficient lead iodide perovskite thin-film solar cells. Angew. Chem. 53(37), 9898-9903 (2014). doi:10.1002/ange.201405334

52. H. Deng, D. Dong, K. Qiao, L. Bu, B. Li et al., Growth, patterning and alignment of organolead iodide perovskite nanowires for optoelectronic devices. Nanoscale 7(9), 4163-4170 (2015). doi:10.1039/c4nr06982j

53. T. Limongi, L. Tirinato, F. Pagliari, A. Giugni, M. Allione, G. Perozziello, P. Candeloro, E. Di Fabrizio, Fabrication and applications of micro/nanostructured devices for tissue engineering. Nano-Micro Lett. 9, 1 (2017). doi:10.1007/s40820-0160103-7

54. Y. Tidhar, E. Edri, H. Weissman, D. Zohar, G. Hodes, D. Cahen, B. Rybtchinski, S. Kirmayer, Crystallization of methyl ammonium lead halide perovskites: implications for photovoltaic applications. J. Am. Chem. Soc. 136(38), 13249-13256 (2014). doi:10.1021/ja505556s

55. T. Baikie, Y. Fang, J.M. Kadro, M. Schreyer, F. Wei et al., Synthesis and crystal chemistry of the hybrid perovskite $\left(\mathrm{CH}_{3}\right.$ $\left.\mathrm{NH}_{3}\right) \mathrm{PbI}_{3}$ for solid-state sensitised solar cell applications. J. Mater. Chem. A 1(18), 5628-5641 (2013). doi:10.1039/ C3TA10518K

56. C.C. Stoumpos, C.D. Malliakas, M.G. Kanatzidis, Semiconducting tin and lead iodide perovskites with organic cations: phase transitions, high mobilities, and near-infrared photoluminescent properties. Inorg. Chem. 52(15), 9019-9038 (2013). doi:10.1021/ic401215x

57. Q. Hu, H. Wu, J. Sun, D. Yan, Y. Gao, J. Yang, Large-area perovskite nanowire arrays fabricated by large-scale roll-to-roll micro-gravure printing and doctor blading. Nanoscale 8(9), 5350-5357 (2016). doi:10.1039/c5nr08277c

58. H. Deng, X. Yang, D. Dong, B. Li, D. Yang et al., Flexible and semitransparent organolead triiodide perovskite network photodetector arrays with high stability. Nano Lett. 15(12), 7963-7969 (2015). doi:10.1021/acs.nanolett.5b03061

59. D. Zhang, S.W. Eaton, Y. Yu, L. Dou, P. Yang, Solution-phase synthesis of cesium lead halide perovskite nanowires. J. Am. Chem. Soc. 137(29), 9230-9233 (2015). doi:10.1021/jacs.5b05404

60. W. Deng, X. Zhang, L. Huang, X. Xu, L. Wang, J. Wang, Q. Shang, S.T. Lee, J. Jie, Aligned single-crystalline perovskite microwire arrays for high-performance flexible image sensors with long-term stability. Adv. Mater. 28(11), 2201-2208 (2016). doi:10.1002/adma.201505126

61. W. Sun, Y. Li, S. Ye, H. Rao, W. Yan et al., High-performance inverted planar heterojunction perovskite solar cells based on a solution-processed $\mathrm{CuO}_{x}$ hole transport layer. Nanoscale 8(20), 10806-10813 (2016). doi:10.1039/c6nr01927g

62. J. Hu, T.W. Odom, C.M. Lieber, Chemistry and physics in one dimension: synthesis and properties of nanowires and nanotubes. Acc. Chem. Res. 32(5), 435-445 (1999). doi:10.1021/ar9700365

63. J.H. Im, J. Luo, M. Franckevicius, N. Pellet, P. Gao et al., Nanowire perovskite solar cell. Nano Lett. 15(3), 2120-2126 (2015). doi:10.1021/acs.nanolett.5b00046

64. E. Edri, S. Kirmayer, M. Kulbak, G. Hodes, D. Cahen, Chloride inclusion and hole transport material doping to improve methyl ammonium lead bromide perovskite-based high open-circuit voltage solar cells. J. Phys. Chem. Lett. 5(3), 429-433 (2014). doi: $10.1021 / j z 402706 q$

65. K. Gesi, Effect of hydrostatic pressure on the structural phase transitions in $\mathrm{CH}_{3} \mathrm{NH}_{3} \mathrm{PbX}_{3}(\mathrm{X}=\mathrm{Cl}, \mathrm{Br}, \mathrm{I})$. Ferroelectrics 203(1), 249-268 (1997). doi:10.1080/00150199708012851

66. K. Park, J.W. Lee, J.D. Kim, N.S. Han, D.M. Jang, S. Jeong, J. Park, J.K. Song, Light-matter interactions in cesium lead halide perovskite nanowire lasers. J. Phys. Chem. Lett. 7(18), 3703-3710 (2016). doi:10.1021/acs.jpclett.6b01821

67. Z. Wang, J. Liu, Z.Q. Xu, Y. Xue, L. Jiang et al., Wavelengthtunable waveguides based on polycrystalline organic-inorganic perovskite microwires. Nanoscale 8(12), 6258-6264 (2016). doi:10.1039/c5nr06262d

68. S. Zhuo, J. Zhang, Y. Shi, Y. Huang, B. Zhang, Self-templatedirected synthesis of porous perovskite nanowires at room temperature for high-performance visible-light photodetectors. Angew. Chem. 127(19), 5785-5788 (2015). doi:10.1002/anie. 201411956

69. X.F. Shen, X.P. Yan, Facile shape-controlled synthesis of wellaligned nanowire architectures in binary aqueous solution. Angew. Chem. Int. Ed. 46(40), 7659-7663 (2007). doi:10.1002/ anie. 200702451

70. M.J. Ashley, M.N. O'Brien, K.R. Hedderick, J.A. Mason, M.B. Ross, C.A. Mirkin, Templated synthesis of uniform perovskite nanowire arrays. J. Am. Chem. Soc. 138(32), 10096-10099 (2016). doi:10.1021/jacs.6b05901

71. M. Spina, E. Bonvin, A. Sienkiewicz, B. Nafradi, L. Forro, E. Horvath, Controlled growth of $\mathrm{CH}_{3} \mathrm{NH}_{3} \mathrm{PbI}_{3}$ nanowires in arrays of open nanofluidic channels. Sci. Rep. 6, 19834 (2016). doi:10. 1038/srep19834

72. C.R. Martin, Nanomaterials-a membrane-based synthetic approach. DTIC Document (1994)

73. D. Routkevitch, T. Bigioni, M. Moskovits, J.M. Xu, Electrochemical fabrication of $\mathrm{CdS}$ nanowire arrays in porous anodic 
aluminum oxide templates. J. Phys. Chem. 100(33), 14037-14047 (1996). doi:10.1021/jp952910m

74. C.R. Martin, Nanomaterials: a membrane-based synthetic approach. Science 266(5193), 1961-1966 (1994). doi:10.1126/ science.266.5193.1961

75. Y. Bekenstein, B.A. Koscher, S.W. Eaton, P. Yang, A.P. Alivisatos, Highly luminescent colloidal nanoplates of perovskite cesium lead halide and their oriented assemblies. J. Am. Chem. Soc. 137(51), 16008-16011 (2015). doi:10.1021/jacs.5b11199

76. Y. Ling, Z. Yuan, Y. Tian, X. Wang, J.C. Wang, Y. Xin, K. Hanson, B. Ma, H. Gao, Bright light-emitting diodes based on organometal halide perovskite nanoplatelets. Adv. Mater. 28(2), 305-311 (2016). doi:10.1002/adma.201503954

77. Z. Yuan, Y. Shu, Y. Tian, Y. Xin, B. Ma, A facile one-pot synthesis of deep blue luminescent lead bromide perovskite microdisks. Chem. Commun. 51(91), 16385-16388 (2015). doi: $10.1039 / \mathrm{c} 5 \mathrm{cc} 06750 \mathrm{~b}$

78. W. Tian, C. Zhao, J. Leng, R. Cui, S. Jin, Visualizing carrier diffusion in individual single-crystal organolead halide perovskite nanowires and nanoplates. J. Am. Chem. Soc. 137(39), 12458-12461 (2015). doi:10.1021/jacs.5b08045

79. Y. Zhao, K. Zhu, Efficient planar perovskite solar cells based on $1.8 \mathrm{eV}$ band gap $\mathrm{CH}_{3} \mathrm{NH}_{3} \mathrm{PbI}_{2} \mathrm{Br}$ nanosheets via thermal decomposition. J. Am. Chem. Soc. 136(35), 12241-12244 (2014). doi:10.1021/ja5071398

80. S.T. Ha, X. Liu, Q. Zhang, D. Giovanni, T.C. Sum, Q. Xiong, Synthesis of organic-inorganic lead halide perovskite nanoplatelets: towards high-performance perovskite solar cells and optoelectronic devices. Adv. Opt. Mater. 2(9), 838-844 (2014). doi:10.1002/adom.201400106

81. Q. Liao, K. Hu, H. Zhang, X. Wang, J. Yao, H. Fu, Perovskite microdisk microlasers self-assembled from solution. Adv. Mater. 27(22), 3405-3410 (2015). doi:10.1002/adma.201500449

82. D. Shi, V. Adinolfi, R. Comin, M. Yuan, E. Alarousu et al., Low trap-state density and long carrier diffusion in organolead trihalide perovskite single crystals. Science 347(6221), 519-522 (2015). doi:10.1126/science.aaa2725

83. Q.A. Akkerman, S.G. Motti, A.R. Srimath Kandada, E. Mosconi, V. D'Innocenzo et al., Solution synthesis approach to colloidal cesium lead halide perovskite nanoplatelets with monolayer-level thickness control. J. Am. Chem. Soc. 138(3), 1010-1016 (2016). doi:10.1021/jacs.5b12124

84. K.H. Wang, L. Wu, L. Li, H.B. Yao, H.S. Qian, S.H. Yu, Largescale synthesis of highly luminescent perovskite-related $\mathrm{CsPb}_{2}$ $\mathrm{Br}_{5}$ nanoplatelets and their fast anion exchange. Angew. Chem. Int. Ed. 55(29), 8328-8332 (2016). doi:10.1002/anie.201602787

85. G. Li, H. Wang, Z. Zhu, Y. Chang, T. Zhang, Z. Song, Y. Jiang, Shape and phase evolution from $\mathrm{CsPBr}_{3}$ perovskite nanocubes to tetragonal $\mathrm{CsPb}_{2} \mathrm{Br}_{5}$ nanosheets with an indirect bandgap. Chem. Commun. 52(75), 11296-11299 (2016). doi:10.1039/ c6cc05877a

86. D.M. Jang, K. Park, D.H. Kim, J. Park, F. Shojaei, H.S. Kang, J.P. Ahn, J.W. Lee, J.K. Song, Reversible halide exchange reaction of organometal trihalide perovskite colloidal nanocrystals for full-range band gap tuning. Nano Lett. 15(8), 5191-5199 (2015). doi:10.1021/acs.nanolett.5b01430

87. L. Dou, A.B. Wong, Y. Yu, M. Lai et al., Atomically thin twodimensional organic-inorganic hybrid perovskites. Science 349(6255), 1518-1521 (2015). doi:10.1126/science.aac7660

88. R. Naphade, S. Nagane, G.S. Shanker, R. Fernandes, D. Kothari, Y. Zhou, N.P. Padture, S. Ogale, Hybrid perovskite quantum nanostructures synthesized by electrospray antisolvent-solvent extraction and intercalation. ACS Appl. Mater. Interfaces 8(1), 854-861 (2016). doi:10.1021/acsami.5b10208

89. Y. Fu, F. Meng, M.B. Rowley, B.J. Thompson, M.J. Shearer, D. Ma, R.J. Hamers, J.C. Wright, S. Jin, Solution growth of single crystal methylammonium lead halide perovskite nanostructures for optoelectronic and photovoltaic applications. J. Am. Chem. Soc. 137(17), 5810-5818 (2015). doi:10.1021/jacs.5b02651

90. J. Song, J. Li, X. Li, L. Xu, Y. Dong, H. Zeng, Quantum dot light-emitting diodes based on inorganic perovskite cesium lead halides $\left(\mathrm{CsPbX}_{3}\right)$. Adv. Mater. 27(44), 7162-7167 (2015). doi:10.1002/adma.201502567

91. D.H. Cao, C.C. Stoumpos, O.K. Farha, J.T. Hupp, M.G. Kanatzidis, 2D homologous perovskites as light-absorbing materials for solar cell applications. J. Am. Chem. Soc. 137(24), 7843-7850 (2015). doi:10.1021/jacs.5b03796

92. E.R. Dohner, E.T. Hoke, H.I. Karunadasa, Self-assembly of broadband white-light emitters. J. Am. Chem. Soc. 136(5), 1718-1721 (2014). doi:10.1021/ja411045r

93. E.R. Dohner, A. Jaffe, L.R. Bradshaw, H.I. Karunadasa, Intrinsic white-light emission from layered hybrid perovskites. J. Am. Chem. Soc. 136(38), 13154-13157 (2014). doi:10.1021/ ja507086b

94. M. Kulbak, D. Cahen, G. Hodes, How important is the organic part of lead halide perovskite photovoltaic cells? Efficient $\mathrm{CsPbBr}_{3}$ cells. J. Phys. Chem. Lett. 6(13), 2452-2456 (2015). doi:10.1021/acs.jpclett.5b00968

95. H. Cho, S.-H. Jeong, M.-H. Park, Y.-H. Kim, C. Wolf et al., Overcoming the electroluminescence efficiency limitations of perovskite light-emitting diodes. Science 350(6265), 1222-1225 (2015). doi:10.1126/science.aad1818

96. Z.K. Tan, R.S. Moghaddam, M.L. Lai, P. Docampo, R. Higler et al., Bright light-emitting diodes based on organometal halide perovskite. Nat. Nanotechnol. 9(9), 687-692 (2014). doi:10. 1038/nnano.2014.149

97. P. Gao, M. Grätzel, M.K. Nazeeruddin, Organohalide lead perovskites for photovoltaic applications. Energy Environ. Sci. 7(8), 2448 (2014). doi:10.1039/c4ee00942h

98. A. Kojima, K. Teshima, T. Miyasaka, Y. Shirai, In novel photoelectrochemical cell with mesoscopic electrodes sensitized by lead-halide compounds (2), Meeting Abstracts, 2006; The Electrochemical Society: pp 397-397. http://ecsdl.org/site/ terms_use

99. I. Chung, B. Lee, J. He, R.P. Chang, M.G. Kanatzidis, All-solidstate dye-sensitized solar cells with high efficiency. Nature 485(7399), 486-489 (2012). doi:10.1038/nature11067

100. J.H. Heo, S.H. Im, J.H. Noh, T.N. Mandal, C.-S. Lim et al., Efficient inorganic-organic hybrid heterojunction solar cells containing perovskite compound and polymeric hole conductors. Nat. Photonics 7(6), 486-491 (2013). doi:10.1038/nphoton. 2013.80

101. W.S. Yang, J.H. Noh, N.J. Jeon, Y.C. Kim, S. Ryu, J. Seo, S.I. Seok, High-performance photovoltaic perovskite layers fabricated through intramolecular exchange. Science 348(6240), 1234-1237 (2015). doi:10.1126/science.aaa9272

102. N.J. Jeon, J.H. Noh, W.S. Yang, Y.C. Kim, S. Ryu, J. Seo, S.I. Seok, Compositional engineering of perovskite materials for high-performance solar cells. Nature 517(7535), 476-480 (2015). doi:10.1038/nature14133

103. A. Swarnkar, A.R. Marshall, E.M. Sanehira, B.D. Chernomordik, D.T. Moore, J.A. Christians, T. Chakrabarti, J.M. Luther, Quantum dot: induced phase stabilization of $\alpha-\mathrm{CsPbI}_{3}$ perovskite for high-efficiency photovoltaics. Science 354(6308), 92-95 (2016). doi:10.1126/science.aag2700

104. G.E. Eperon, V.M. Burlakov, P. Docampo, A. Goriely, H.J. Snaith, Morphological control for high performance, solutionprocessed planar heterojunction perovskite solar cells. Adv. Funct. Mater. 24(1), 151-157 (2014). doi:10.1002/adfm. 201302090

105. C.W. Chen, H.W. Kang, S.Y. Hsiao, P.F. Yang, K.M. Chiang, H.W. Lin, Efficient and uniform planar-type perovskite solar 
cells by simple sequential vacuum deposition. Adv. Mater. 26(38), 6647-6652 (2014). doi:10.1002/adma.201402461

106. D.T. Moore, H. Sai, K.W. Tan, L.A. Estroff, U. Wiesner, Impact of the organic halide salt on final perovskite composition for photovoltaic applications. APL Mater. 2(8), 081802 (2014). doi:10.1063/1.4886275

107. B.-E. Cohen, S. Gamliel, L. Etgar, Parameters influencing the deposition of methylammonium lead halide iodide in hole conductor free perovskite-based solar cells. APL Mater. 2(8), 081502 (2014). doi:10.1063/1.4885548

108. Z. Yu, S. Fan, Complete optical isolation created by indirect interband photonic transitions. Nat. Photonics 3(2), 91-94 (2009). doi:10.1364/FIO.2008.FMG2

109. X. Gao, Y. Cui, R.M. Levenson, L.W. Chung, S. Nie, In vivo cancer targeting and imaging with semiconductor quantum dots. Nat. Biotechnol. 22(8), 969-976 (2004). doi:10.1038/nbt994

110. G. Konstantatos, E.H. Sargent, Nanostructured materials for photon detection. Nat. Nanotechnol. 5(6), 391-400 (2010). doi:10.1038/nnano.2010.78

111. J. He, K. Qiao, L. Gao, H. Song, L. Hu, S. Jiang, J. Zhong, J. Tang, Synergetic effect of silver nanocrystals applied in $\mathrm{PbS}$ colloidal quantum dots for high-performance infrared photodetectors. ACS Photonics 1(10), 936-943 (2014). doi:10.1021/ ph500227u

112. B. Zu, B. Lu, Y. Guo, T. Xu, X. Dou, Simple metal/SiO $\mathrm{S}_{2} / \mathrm{Si}$ planar photodetector utilizing leakage current flows through a $\mathrm{SiO}_{2}$ layer. J. Mater. Chem. C 2(11), 2045-2050 (2014). doi:10. 1039/C3TC32242D

113. R. Yu, C. Pan, Y. Hu, L. Li, H. Liu, W. Liu, S. Chua, D. Chi, Z.L. Wang, Enhanced performance of GaN nanobelt-based photodetectors by means of piezotronic effects. Nano Res. 6(10), 758-766 (2013). doi:10.1007/s12274-013-0354-2

114. H. Zhu, X. Chen, J. Cai, Z. Wu, 4H-SiC ultraviolet avalanche photodetectors with low breakdown voltage and high gain. Solid State Electron. 53(1), 7-10 (2009). doi:10.1016/j.sse.2008.09. 002

115. F. Xia, T. Mueller, Y.-M. Lin, A. Valdes-Garcia, P. Avouris, Ultrafast graphene photodetector. Nat. Nanotechnol. 4(12), 839-843 (2009). doi:10.1038/nnano.2009.292

116. S. Wu, Z. Zeng, Q. He, Z. Wang, S.J. Wang, Y. Du, Z. Yin, X. Sun, W. Chen, H. Zhang, Electrochemically reduced singlelayer $\mathrm{MoS}_{2}$ nanosheets: characterization, properties, and sensing applications. Small 8(14), 2264-2270 (2012). doi:10.1002/smll. 201200044

117. W. Jin, Z. Gao, Y. Zhou, B. Yu, H. Zhang, H. Peng, Z. Liu, L. Dai, Novel graphene-oxide-semiconductor nanowire phototransistors. J. Mater. Chem. C 2(9), 1592-1596 (2014). doi:10. $1039 / \mathrm{c} 3 \mathrm{tc} 32123 \mathrm{a}$

118. G. Konstantatos, M. Badioli, L. Gaudreau, J. Osmond, M. Bernechea, F.P.G. de Arquer, F. Gatti, F.H. Koppens, Hybrid graphene-quantum dot phototransistors with ultrahigh gain. Nat. Nanotechnol. 7(6), 363-368 (2012). doi:10.1038/nnano.2012.60

119. S.W. Eaton, M. Lai, N.A. Gibson, A.B. Wong, L. Dou et al., Lasing in robust cesium lead halide perovskite nanowires. Proc. Natl. Acad. Sci. U.S.A. 113(8), 1993-1998 (2016). doi:10.1073/ pnas. 1600789113

120. R. Yan, D. Gargas, P. Yang, Nanowire photonics. Nat. Photonics 3(10), 569-576 (2009). doi:10.1038/nphoton.2009. 184

121. H. Zhou, Q. Chen, G. Li, S. Luo, T.-B. Song et al., Interface engineering of highly efficient perovskite solar cells. Science 345(6196), 542-546 (2014). doi:10.1126/science.1254050

122. S.D. Stranks, G.E. Eperon, G. Grancini, C. Menelaou, M.J. Alcocer et al., Electron-hole diffusion lengths exceeding 1 micrometer in an organometal trihalide perovskite absorber.
Science 342(6156), 341-344 (2013). doi:10.1126/science. 1243982

123. G. Xing, N. Mathews, S. Sun, S.S. Lim, Y.M. Lam, M. Grätzel, S. Mhaisalkar, T.C. Sum, Long-range balanced electron-and hole-transport lengths in organic-inorganic $\mathrm{CH}_{3} \mathrm{NH}_{3} \mathrm{PbI}_{3}$. Science 342(6156), 344-347 (2013). doi:10.1126/science.1243167

124. F. Deschler, M. Price, S. Pathak, L.E. Klintberg, D.-D. Jarausch et al., High photoluminescence efficiency and optically pumped lasing in solution-processed mixed halide perovskite semiconductors. J. Phys. Chem. Lett. 5(8), 1421-1426 (2014). doi:10. 1021/jz5005285

125. G. Xing, N. Mathews, S.S. Lim, N. Yantara, X. Liu, D. Sabba, M. Grätzel, S. Mhaisalkar, T.C. Sum, Low-temperature solutionprocessed wavelength-tunable perovskites for lasing. Nat. Mater. 13(5), 476-480 (2014). doi:10.1038/nmat3911

126. L.K. Van Vugt, S. Rühle, D. Vanmaekelbergh, Phase-correlated nondirectional laser emission from the end facets of a $\mathrm{ZnO}$ nanowire. Nano Lett. 6(12), 2707-2711 (2006). doi:10.1021/ n10616227

127. B. Mayer, D. Rudolph, J. Schnell, S. Morkötter, J. Winnerl et al., Lasing from individual GaAs-AlGaAs core-shell nanowires up to room temperature. Nat. Commun. 4(1), 2931 (2013). doi:10. 1038/ncomms3931

128. H. Zhu, Y. Fu, F. Meng, X. Wu, Z. Gong et al., Lead halide perovskite nanowire lasers with low lasing thresholds and high quality factors. Nat. Mater. 14(6), 636-642 (2015). doi:10.1038/ nmat4271

129. Y. Fu, H. Zhu, A.W. Schrader, D. Liang, Q. Ding et al., Nanowire lasers of formamidinium lead halide perovskites and their stabilized alloys with improved stability. Nano Lett. 16(2), 1000-1008 (2016). doi:10.1021/acs.nanolett.5b04053

130. H. Huang, B. Chen, Z. Wang, T.F. Hung, A.S. Susha, H. Zhong, A.L. Rogach, Water resistant $\mathrm{CsPbX}_{3}$ nanocrystals coated with polyhedral oligomeric silsesquioxane and their use as solid state luminophores in all-perovskite white light-emitting devices. Chem. Sci. 7(9), 5699-5703 (2016). doi:10.1039/c6sc01758d

131. F. Palazon, Q.A. Akkerman, M. Prato, L. Manna, X-ray lithography on perovskite nanocrystals films: from patterning with anion-exchange reactions to enhanced stability in air and water. ACS Nano 10(1), 1224-1230 (2015). doi:10.1021/acs nano.5b06536

132. V.C. Nair, C. Muthu, A.L. Rogach, R. Kohara, V. Biju, Channeling exciton migration into electron transfer in formamidinium lead bromide perovskite nanocrystal/fullerene composites. Angew. Chem. 56(5), 1214-1218 (2016). doi:10. 1002/ange.201610070

133. M. Meyns, M. Perálvarez, A. Heuer-Jungemann, W. Hertog, M. Ibáñez et al., Polymer-enhanced stability of inorganic perovskite nanocrystals and their application in color conversion LEDs. ACS Appl. Mater. Interfaces 8(30), 19579-19586 (2016). doi:10.1021/acsami.6b02529

134. C. Sun, Y. Zhang, C. Ruan, C. Yin, X. Wang, Y. Wang, W.W. $\mathrm{Yu}$, Efficient and stable white LEDs with silica-coated inorganic perovskite quantum dots. Adv. Mater. 28(45), 10088-10094 (2016). doi:10.1002/adma.201603081

135. F. Palazon, F. Di Stasio, Q.A. Akkerman, R. Krahne, M. Prato, L. Manna, Polymer-free films of inorganic halide perovskite nanocrystals as UV-to-white color-conversion layers in LEDs. Chem. Mater. 28(9), 2902-2906 (2016). doi:10.1021/acs.chem mater.6b00954

136. L. Protesescu, S. Yakunin, M.I. Bodnarchuk, F. Bertolotti, N. Masciocchi, A. Guagliardi, M.V. Kovalenko, Monodisperse formamidinium lead bromide nanocrystals with bright and stable green photoluminescence. J. Am. Chem. Soc. 138(43), 14202-14205 (2016). doi:10.1021/jacs.6b08900 